ISSN: 0213-2060

DOI: http://dx.doi.org/10.14201/shhme20143273101

\title{
TITULARIDAD SEÑORIAL, EXPLOTACIÓN Y RENTAS DE LOS RECURSOS AGRÍCOLAS, GANADEROS Y FORESTALES EN EL PAÍS VASCO AL FINAL DE LA EDAD MEDIA ${ }^{1}$
}

\author{
Seigneurial Titularity, Exploitation and Rents of the Agricultural, Livestock and \\ Forestry Resources of the Basque Country at the End of the Middle Ages
}

José Ramón DÍAZ DE DURANA

Depto. de Historia Medieval, Moderna y de América. Facultad de Letras. Universidad del País Vasco/Euskal Herriko Unibertsitatea. Paseo de la Universidad, 5. E-01006 VITORIA-GASTEIZ. C. e.: joseramon. diazdedurana@ehu.es

Arsenio DACOSTA

Centro Asociado de la UNED de Zamora. C/ San Torcuato, 43.E-49014 ZAMORA. C. e.: adacosta@ zamora.uned.es

Recibido: 2014-04-04

Revisado: 2014-09-24

Aceptado: 2014-10-03

BIBLID [0213-2060(2014)32;73-101]

RESUMEN: Este estudio aborda la titularidad señorial, la explotación y las rentas sobre los recursos agrícolas, ganaderos y forestales en el País Vasco al final de la Edad Media. A partir de la documentación publicada e inédita estudia tres casos que iluminan distintas parcelas del mundo rural vasco bajomedieval. En primer lugar, la gestión de un pequeño señorío rural a través de la contabilidad del mayordomo de las seńoras de Hueto y Mártioda entre 1404 y 1428. En segundo lugar, la gestión del patrimonio rural de los parientes mayores vizcaínos y guipuzcoanos en la que juegan un papel central los bienes pertenecientes a las iglesias de

1 Este artículo se enmarca en el proyecto de investigación HAR2013-44093-P, De la lucha de bandos a la hidalguía universal. Transformaciones sociales, politicas e ideológicas en el Pais Vasco (siglos XIV-XVI), del Ministerio de Economía y Competitividad del Gobierno de España, y en los trabajos del Grupo Consolidado IT-600-13 del Gobierno Vasco. 
JOSÉ RAMÓN DÍAZ DE DURANA Y ARSENIO DACOSTA

TITULARIDAD SEÑORIAL, EXPLOTACIÓN Y RENTAS DE LOS RECURSOS AGRÍCOLAS, GANADEROS Y FORESTALES EN EL PAÍS VASCO AL FINAL DE LA EDAD MEDIA

patronato laico. Finalmente, la gestión de los bienes rústicos de un mercader vitoriano entre 1482 y 1501 . Tres modelos que aparentemente evidencian intereses y necesidades diferentes, pero que implican una gestión cercana y exigente.

Palabras clave: Titularidad. Explotación. Rentas. Señorío. Gestión patrimonial. Patronato. País Vasco. Baja Edad Media.

ABSTRACT: This study looks at the seigneurial titularity, exploitation and rents of the agricultural, livestock and forestry resources of the Basque Country at the end of the Middle Ages. Working from both published and unpublished documentation we will study three cases that shed light on different aspects of rural life in late-medieval Basque society. Firstly, the management of the small rural seigneury of the Lady of Hueto y Martioda between 1404 and 1428, as seen through the accounts of its steward. Secondly, the management of the rural wealth of the Vizcayan and Guipuzcoan heads of lineages, in which the role of churches of lay patronage plays a central role. And finally, the management of the rural possessions of a merchant of Victoria between 1482 and 1501. They are three models which seem to remit to completely different interests and needs, but which in fact in all three cases imply a similarly thorough management style.

Keywords: Seigneurial titularity. Exploitation. Rents. Seigneury. Estate management. Patronage. Basque Country. Late medieval.

SUMARIO: 0 Introducción. 1 Estado de la cuestión. 2 Titularidad y gestión de los bienes agropecuarios en el ámbito vasco. 3 La contabilidad del señor. El señorío de dońa Blanca y dońa Leonor de Mendoza sobre las aldeas de los Huetos y Mártioda. 4 La gestión de los bienes rústicos de los seńores sin señorío. 5 La contabilidad y la gestión del mercader: el caso de Juan Sánchez de Bilbao. 6 Conclusiones.

\section{INTRODUCCIÓN}

El trabajo que presentamos estudia la titularidad señorial, la explotación y las rentas sobre los recursos agrícolas, ganaderos y forestales en el País Vasco al final de la Edad Media. Quizá el lector, con razón, se pregunta por qué los autores visitan de nuevo un territorio intensamente roturado en el pasado en otras latitudes. Lo hacemos porque consideramos que los problemas planteados no se han abordado in extenso en el caso vasco y porque, para su mejor comprensión, necesitan de algunas precisiones adicionales que necesariamente obligan a focalizar la observación para entender en toda su complejidad los rasgos y la evolución de los conceptos que proponemos analizar.

Para abordar ese objetivo utilizaremos documentación inédita y publicada procedente de archivos familiares o señoriales y la depositada en el Archivo de la Real Chancillería de Valladolid. Un conjunto de informaciones que completaremos con la literatura histórica sobre el problema objeto de estudio. Dividiremos el trabajo en tres apartados. En primer lugar, se abordará un breve estado de la cuestión que acerque al lector a los avances en la materia obtenidos durante los últimos ańos por la historiografía. En segundo lugar, 
JOSÉ RAMÓN DÍAZ DE DURANA Y ARSENIO DACOSTA

TITULARIDAD SEÑORIAL, EXPLOTACIÓN Y RENTAS DE LOS RECURSOS AGRÍCOLAS,

GANADEROS Y FORESTALES EN EL PAÍS VASCO AL FINAL DE LA EDAD MEDIA

intentaremos proporcionar un conjunto de aclaraciones sobre lo seńorial en aquellos territorios donde no hay seńoríos y las consecuencias sobre la titularidad, explotación y rentas sobre los recursos del sector primario. Finalmente, analizaremos tres casos. El primero de ellos, lo estudiaremos a partir de la «contabilidad» elaborada por el mayordomo de doña Blanca y doña Leonor de Mendoza que registra los ingresos procedentes de varias aldeas que pertenecían a su señorío y los gastos dedicados al mantenimiento de las doncellas; puede considerarse este un prototipo de gestión de un pequeño señorío rural. Para el segundo, con el fin de averiguar cómo gestionaban los parientes mayores sus bienes en sus áreas de influencia, nos apoyaremos en los testimonios conservados sobre la explotación de recursos del sector primario pertenecientes a las iglesias de patronato laico, en los memoriales de bienes de distintos linajes, en la vinculación de bienes a mayorazgos, etc. Finalmente, analizaremos cómo administraron sus bienes rústicos en las aldeas de la jurisdicción de Vitoria el mercader Juan Sánchez de Bilbao y su hijo a través de las anotaciones - un total de 139 noticias de contratos- que realizaron sobre cada uno de ellos durante un corto periodo de tiempo, entre 1482 y 1501.

\section{Estado DE LA CUESTIÓN}

En los estudios sobre el mundo rural vasco es imprescindible la referencia a los elaborados por Julio Caro Baroja $\mathrm{a}^{2}$. No obstante, los avances en la investigación sobre la época medieval se deben al impulso y a la maestría del profesor José Ángel García de Cortázar. El mejor exponente son sus trabajos durante los ańos setenta y ochenta del siglo $\mathrm{xx}^{3}$. Cuando

2 Entre otros, por su repercusión, El carnaval. Madrid: Taurus, 1989; De la vida rural vasca. San Sebastián: Txertoa, 1974; Vecindad, familia, técnica. San Sebastián: Txertoa, 1974.

3 «El fortalecimiento de la burguesía como grupo social dirigente de la sociedad vascongada a lo largo de los siglos XIV y XV». En La sociedad vasca rural y urbana en el marco de la crisis de los siglos XIV y XV. Bilbao: Diputación Provincial de Vizcaya, 1975, pp. 283-312; «El Señorío de Vizcaya hasta el siglo xvI». En Historia del Pueblo Vasco. San Sebastián: Erein, 1978, vol. I, pp. 223-267; «La organización del territorio en la formación de Álava y Vizcaya en los siglos viII a fines del XI». En El hábitat en la historia de Euskadi. Bilbao: Colegio de Arquitectos Vasco-Navarro, 1981, pp. 135-154; «Espacio y poblamiento en la Vizcaya altomedieval: de la comarca al caserío en los siglos XI al xiII». En la España Medieval, 1982, vol. II, pp. 349365; «Les communautés villageoises du nord de la Péninsule Ibérique au Moyen Âge». En Les communautés villageoises en Europe Occidentale du Moyen Âge aux temps Modernes, Flaran, 1982, vol. 4, pp. 67-73; «La sociedad guipuzcoana antes del Fuero de San Sebastián». En Congreso «El Fuero de San Sebastián y su época». San Sebastián: Eusko Ikaskuntza, 1982, pp. 89-109; «La sociedad alavesa medieval antes de la concesión del Fuero de Vitoria». En Vitoria en la Edad Media. Vitoria-Gasteiz: Ayuntamiento de Vitoria-Gasteiz, 1982, pp. 89-114; «La sociedad vizcaína altomedieval: De los sistemas de parentesco de base ganadera a la diversificación y jerarquización sociales de base territorial». En Congreso de Estudios Históricos Vizcaya en la Edad Media. San Sebastián: Eusko Ikaskuntza, 1986, pp. 64-81; «Espacio y hombre en la Espańa norteńa en la Edad Media». Anales de la Universidad de Alicante. Historia Medieval, 1987, vol. 6, pp. 49-74; «Poblamiento y organización social del espacio vasco en la Edad Media». En II Congreso Mundial Vasco. San Sebastián: Txertoa, 1988, vol. II, pp. 421-443; «Medioevo y mundo rural». En Los vascos a través de la historia: comportamientos, mentalidades y vida cotidiana. San Sebastián: Guipuzkoako Kutxa, 1989, pp. 68-91. Todos ellos publicados también en Díaz de Durana, José Ramón (ed.). Investigaciones sobre historia medieval del País Vasco (1965-2005). 20 artículos y una entrevista del profesor José Ángel García de Cortázar. Bilbao: Servicio Editorial de la Universidad del País Vasco, 2005. 
JOSÉ RAMÓN DÍAZ DE DURANA Y ARSENIO DACOSTA

TITULARIDAD SEÑORIAL, EXPLOTACIÓN Y RENTAS DE LOS RECURSOS AGRÍCOLAS, GANADEROS Y FORESTALES EN EL PAÍS VASCO AL FINAL DE LA EDAD MEDIA

en 1977 presentó una primera revisión sobre la producción historiográfica de tema medieval vascongado destacó el mundo rural como una de las parcelas descuidadas ${ }^{4}$. Su esfuerzo desde la Universidad de Cantabria y la creación de la Facultad de Letras de la Universidad del País Vasco fueron modificando aquel balance -en realidad desolador-, aunque su observación en torno a los estudios sobre las actividades del sector primario era contundente: un yermo investigador "intensísimo". Durante los años ochenta, la producción se incrementó notablemente. La celebración durante esos años de distintos congresos permitió la publicación de numerosos trabajos, aunque entre los más significativos en el plano de la historia rural bajomedieval destacan a nuestro juicio los elaborados por el propio García de Cortázar y su equipo sobre las actividades del sector primario en el espacio vizcaíno ${ }^{6}$ y la publicación de la tesis doctoral de José Ramón Díaz de Durana sobre la Álava bajomedieval ${ }^{7}$. Este último autor publicó en 1990, en las páginas de esta revista, «La recuperación del siglo XV en el nordeste de la Corona de Castilla» dedicado esencialmente a la caracterización y las consecuencias de ese proceso: aumento de la producción cerealista, modificaciones en el paisaje, consolidación de la especialización vitivinícola, etc. ${ }^{8}$.

Durante los años noventa, como en otras áreas peninsulares ${ }^{9}$, se produjo un espectacular avance en la publicación de fuentes documentales ${ }^{10} \mathrm{y}$ en el conocimiento de nuevos datos arqueológicos, también en lo referente a los siglos bajomedievales ${ }^{11}$. Las nuevas investigaciones sobre lo rural fueron diluyéndose en el campo de la historia social. Los trabajos publicados por los autores que firman este artículo y por los miembros del equipo de trabajo del que forman parte son buena prueba de ello. Durante estos ańos hemos dedicado nuestra actividad a la publicación de fuentes útiles para el estudio de la historia rural ${ }^{12} \mathrm{y}$ de estudios que abordan

4 García de Cortázar, José Ángel. «Los estudios de tema medieval vascongado: un balance de las aportaciones de los últimos años». Saioak, 1977, vol. 1, pp. 181-201.

5 García De Cortázar, José Ángel; Bermejo, Manuel; Peña, Esther y Salas, Diana. «Los estudios históricos de tema medieval (1975-1986): Cantabria-País Vasco-Navarra-Rioja», Studia Historica. Historia Medieval, 1988, vol. VI, pp. 27-56, especialmente p. 32.

6 García de Cortázar, José Ángel; Arízaga, Beatriz; Ríos, M. ${ }^{a}$ Luz y Val, M. ${ }^{a}$ Isabel del. Vizcaya en la Edad Media. Evolución demográfica, económica, social y politica de la comunidad vizcaína medieval. San Sebastián: Haranburu, 1985, vol. II, pp. 9-116.

7 Díaz de Durana, José Ramón. Álava en la Baja Edad Media. Crisis, recuperación y transformaciones socioeconómicas (c. 1250-1525). Vitoria: Diputación Foral de Álava, 1986.

8 Studia Historica. Historia Medieval, 1990, vol. VIII, pp. 79-115.

9 García de Cortázar, José Ángel y Martínez Sopena, Pascual. «Los estudios sobre historia rural de la sociedad medieval hispanocristiana». En Alfonso, Isabel (ed.). La Historia rural de las sociedades medievales europeas. Valencia: PUV, pp. 97-143. Véase también el trabajo introductorio de Alfonso, Isabel. "Las historiografías nacionales sobre el mundo rural medieval: una aproximación comparativa», pp. 11-30.

10 La mejor prueba es la publicación de la Colección de fuentes documentales del País Vasco, publicada por la Sociedad de Estudios Vascos/Eusko Ikaskuntza, que el lector puede encontrar en pdf en <http://www. eusko-ikaskuntza.org/es/publicaciones/colecciones/fuentesmedievales/>.

11 Basta acercarse por ejemplo a una de las últimas publicaciones de Quirós, José Antonio. Arqueología del campesinado medieval: la aldea de Zaballa. Bilbao: Universidad del País Vasco, 2012; o a la muy reciente de Azkarate, Agustín y Solaun, José Luis. Arqueología e historia de una ciudad. Los origenes de Vitoria-Gasteiz. Bilbao: Universidad del País Vasco, 2014, 2 vols., para darse cuenta de la importancia de la arqueología en el análisis histórico actual.

12 Lema, José Ángel; Fernández de Larrea, Jon Andoni; García, Ernesto; Munita, José Antonio y Díaz de Durana, José Ramón. Los señores de la guerra y de la tierra: nuevos textos para el estudio de los Parientes 
JOSÉ RAMÓN DÍAZ DE DURANA Y ARSENIO DACOSTA

TITULARIDAD SEÑORIAL, EXPLOTACIÓN Y RENTAS DE LOS RECURSOS AGRÍCOLAS,

GANADEROS Y FORESTALES EN EL PAÍS VASCO AL FINAL DE LA EDAD MEDIA

el análisis del léxico ${ }^{13}$, los distintos recursos del sector primario -agricultura ${ }^{14}$, ganadería ${ }^{15}$, explotación forestal para la elaboración de hierro ${ }^{16}$-, la organización de la sociedad rural alavesa, guipuzcoana y vizcaína -los linajes ${ }^{17}$, la familia ${ }^{18}$-, las bases del poder de los parientes mayores ${ }^{19}$,

Mayores guipuzcoanos (1265-1548). San Sebastián: Diputación Foral de Guipúzcoa, 2000; Lema, José Ángel; Fernández de Larrea, Jon Andoni; Larrañaga Zulueta, Miguel; García, Ernesto; Munita, José Antonio y Díaz de Durana, José Ramón. El triunfo de las elites urbanas guipuzcoanas: nuevos textos para el estudio del gobierno de las villas y de la Provincia (1412-1539). San Sebastián: Diputación Foral de Guipúzcoa, 2000; Goicolea, Francisco J.; Villanueva, Eider; Lema, José Ángel; Fernández de Larrea, Jon Andoni; Munita, José Antonio y Díaz de Durana, José Ramón. Honra de hidalgos, yugo de labradores: nuevos textos para el estudio de la sociedad rural alavesa (1332-1521). Bilbao: Universidad del País Vasco, 2005; DAcosta, Arsenio; Lema, José Ángel; Munita, José Antonio y Díaz de Durana, José Ramón. Poder y privilegio. Nuevos textos para el estudio de la nobleza vizcaina al final de la Edad Media (1416-1527). Bilbao: Universidad del País Vasco, 2010; Paz Moro, Agurtzane. El monasterio de Barría. Historia y documentos (1532-1524). Bilbao: Universidad del País Vasco, 2013; Munita, José Antonio; Lema, José Ángel; Dacosta, Arsenio; Paz, Agurtzane y Díaz de Durana, José Ramón. "En tiempo de ruidos e bandos". Nuevos textos para el estudio de los linajes vizcaínos: los Barroeta de la merindad de Marquina (1355-1547). Bilbao: Universidad del País Vasco, 2014.

13 Líbano, M. a Ángeles y Villacorta, Consuelo. Paisaje rural y explotación agropecuaria: Léxico de los recursos naturales y de la vida cotidiana en el aragonés, navarro y romance vasco, s. XIII-XVI. Zaragoza: Universidad de Zaragoza, 2013.

14 Díaz de Durana, José Ramón. «El mundo rural guipuzcoano al final de la Edad Media: progreso agrícola, gestión y explotación de la tierra». En la España medieval, 1998, vol. 21, pp. 69-96.

15 Díaz de Durana, José Ramón. «Transformaciones en la titularidad y aprovechamiento de los seles en Guipúzcoa (1450-1550)». Zainak. Cuadernos de Antropología y Etnografía, Sociedad de Estudios Vascos, 1998, vol. 17, pp. 19-31; Díaz de Durana, José Ramón. "Para una historia del monte y del bosque en la Guipúzcoa bajomedieval: los seles. Titularidad, formas de cesión y de explotación». Anuario de Estudios Medievales, 2001, vol. 31, n.o 1, pp. 49-73; Díaz de Durana, José Ramón y Fernández de Larrea, Jon Andoni. "Economía ganadera y medio ambiente: Guipúzcoa y el Noreste de Navarra en la Baja Edad Media». Revista de Historia Agraria. Revista de Agricultura e Historia Rural, 2002, vol. 27, pp. 43-64; Díaz DE Durana, José Ramón y Fernández de Larrea, Jon Andoni. "Análisis comparado de dos modelos de explotación ganadera al final de la Edad Media: seles guipuzcoanos y trashumancia nororiental navarra». En II Congreso Internacional "Historia de los Pirineos». Medievalis Historia Pyrenaica. Girona: Centre Associat de la UNEDGirona, 2006, pp. 495-514.

16 Dacosta, Arsenio. «El hierro y los linajes de Vizcaya en el siglo xv: fuentes de renta y competencia económica». Studia Historica. Historia Medieval, 1997, vol. XV, pp. 69-102.

17 Marín Paredes, José Antonio. "Semejante Pariente Mayor». Parentesco, solar, comunidad y linaje en la institución de un pariente mayor en Guipuzkoa: los señores del solar de Oñaz y Loyola. San Sebastián: Diputación Foral de Gipuzkoa, 1998; Dacosta, Arsenio. Los linajes de Bizkaia en la baja Edad Media: poder, parentesco y conflicto. Bilbao: Universidad del País Vasco, 2004; Díaz DE Durana, José Ramón. La otra nobleza. Escuderos e hidalgos sin nombre y sin historia. Hidalgos e hidalguía universal en el País Vasco al final de la Edad Media (1250-1525). Bilbao: Universidad del País Vasco, 2004.

18 Díaz de Durana, José Ramón. "La familia en la cornisa cantábrica al final de la Edad Media». En La familia en la Historia. Salamanca: Ediciones Universidad de Salamanca, 2009, pp. 63-88.

19 Díaz de Durana, José Ramón. «Aproximación a las bases materiales del poder de los Parientes Mayores guipuzcoanos en el mundo rural: hombres, seles, molinos y patronatos». En Díaz DE Durana, José Ramón (ed.). La lucha de bandos en el País Vasco: de los parientes mayores a la hidalguía universal. Guipúzcoa, de los Bandos a la Provincia (ss. XIV a XVI). Bilbao: Universidad del País Vasco, 1998, pp. 235-260; Díaz de Durana, José Ramón. «Las bases materiales del poder de los Parientes Mayores guipuzcoanos: los molinos. Formas de apropiación y explotación, rentas y enfrentamientos en torno a la titularidad y derechos de uso (ss. XIV a Xvi)». Studia Historica. Historia Medieval, 1997, vol. XV, pp. 41-68; Díaz de Durana, José Ramón. "Patronatos, patronos, clérigos y parroquianos. Los derechos de patronazgo sobre monasterios e iglesias como fuente de renta e instrumento de control y dominación de los Parientes Mayores guipuzcoanos 
JOSÉ RAMÓN DÍAZ DE DURANA Y ARSENIO DACOSTA

TITULARIDAD SEÑORIAL, EXPLOTACIÓN Y RENTAS DE LOS RECURSOS AGRÍCOLAS,

GANADEROS Y FORESTALES EN EL PAÍS VASCO AL FINAL DE LA EDAD MEDIA

sus niveles de renta ${ }^{20}$, la condición del campesinado ${ }^{21}$, los conflictos en el mundo rural ${ }^{22}$, el discurso político de los protagonistas de las luchas sociales ${ }^{23}$, la fiscalidad ${ }^{24}$, la evolución económica ${ }^{25}$, etc.

Este panorama nos ofrece una base de investigación solvente pero, como veremos, quedan enormes lagunas por cubrir que, según retrocedemos en el tiempo, y a pesar de los denodados esfuerzos de García de Cortázar, se convierten en verdaderos abismos.

\section{TitulARIDAD y GESTIÓN DE LOS BIENES AGROPECUARIOS EN EL ÁMBITO VASCO}

Pretendemos centrar nuestro estudio sobre la titularidad señorial, la explotación y las rentas sobre los recursos agrí́colas, ganaderos y forestales en el País Vasco. Pero ¿cómo hacerlo allí donde nunca hubo señoríos, donde aparecieron muy avanzada la Edad Media o donde el señor era el rey? Por ejemplo, las actuales tierras guipuzcoanas -a excepción del señorío de Ońate, que se incorporó a la Provincia en 1845- permanecieron siempre en el realengo castellano desde $1200^{26}$. Por el contrario, las tierras de la actual Vizcaya conformaron un señorío -cuyos perfiles físicos ya se habían concretado para

(siglos XIV a XVI)». Hispania Sacra, 1998, vol. L, n. ${ }^{\circ}$ 102, pp. 467-508; DAcosta, Arsenio. «Patronos y linajes en el Señorío de Bizkaia. Materiales para una cartografía del poder en la baja Edad Media». Vasconia, 1999, vol. 29, pp. 21-46.

20 DACOsTa, Arsenio. «Las fuentes de renta del linaje de Salazar: aportación al estudio de las haciendas nobiliarias en la corona de Castilla durante la Baja Edad Media». En Díaz de Durana, José Ramón y Reguera, Iñaki (eds.). Lope García de Salazar: banderizo y cronista. Portugalete: Ayuntamiento de Portugalete, 2002, pp. 41-64.

${ }_{21}$ Díaz de Durana, José Ramón. «Sobre la condición hidalga o pechera del campesinado en el entorno de la cordillera cantábrica al final de la Edad Media». En Sesma, José Ángel y Laliena, Carlos (coords.). La pervivencia del concepto. Nuevas reflexiones sobre la ordenación social del espacio en la Edad Media. Zaragoza: Gobierno de Aragón, 2008, pp. 381-408.

22 Díaz de Durana, José Ramón. «Conflictos sociales en el mundo rural guipuzcoano a fines de la Edad Media: los campesinos protagonistas de la resistencia antiseńorial». Hispania, 1999, vol. LIX, n. ${ }^{\circ}$ 202, pp. 433-455.

23 Díaz de Durana, José Ramón y Fernández de Larrea, Jon Andoni. «El discurso político de los protagonistas de las luchas sociales en el País Vasco al final de la Edad Media (1300-1525)». En Alfonso, Isabel; Escalona, Julio y Martin, Georges (dirs.). Lucha politica. Condena y legitimación en la España medieval. Lyon: Cahiers de Linguistique et de Civilisation hispaniques médiévales. Annexe 16, 2004, pp. 313316; Dacosta, Arsenio. "Historiografía y bandos. Reflexiones acerca de la crítica y justificación de la violencia banderiza en su contextom. En Díaz de Durana, La lucha de bandos en el País Vasco, pp. 121-148.

24 Lema Pueyo, José Ángel. «Los Libros de Estimaciones del Valle de Oiartzun: aspectos paleográficos y diplomáticos». En IrIJOA, Iago y Lema, José Ángel (eds.). Documentación medieval del Archivo Municipal de Oiartzun. I. Libros de estimaciones fiscales de vecinos y bienes raíces (1499-1520). Donostia: Eusko Ikaskuntza, 2011; Díaz de Durana, José Ramón. «Urundiru, que queryan desir dinero de harina». Revista de Cultura e Investigación Vasca Sancho el Sabio (en adelante Sancho el Sabio), 1998, vol. 9, pp. 155-160.

25 Fernández de Larrea, Jon Andoni. «Crisis y recuperación del mundo agrario en el País Vasco (siglos XiII-Xv)». En Barruso, Pedro y Lema, José Ángel (eds.). Historia del País Vasco. Edad Media (siglos $V$-XV). San Sebastián: Hiria, 2004, pp. 337-403.

26 Tena, María Soledad. «Ambitos jurisdiccionales en el País Vasco durante la Baja Edad Media: Panorámica de un territorio diverso y fragmentado». En Pueblos, naciones y estados en la historia. Salamanca: Ediciones Universidad de Salamanca, 1994, pp. 34-38. 
JOSÉ RAMÓN DÍAZ DE DURANA Y ARSENIO DACOSTA

TITULARIDAD SEÑORIAL, EXPLOTACIÓN Y RENTAS DE LOS RECURSOS AGRÍCOLAS,

GANADEROS Y FORESTALES EN EL PAÍS VASCO AL FINAL DE LA EDAD MEDIA

las primeras décadas del siglo XII- que se transmitió hereditariamente dentro del linaje de los López de Haro y los Lara hasta que, en 1379, se incorporó definitivamente a la Corona castellana manteniendo desde entonces su entidad indivisible como mayorazgo y su régimen de gobierno conforme a los fueros jurados por el señor ${ }^{27}$. Finalmente, las tierras alavesas - a excepción de Vitoria y su término- fueron entregadas a los señores -Mendoza, Ayala, Sarmiento, etc.- con la jurisdicción civil y criminal, vasallos, montes, tributos, etc. ${ }^{28}$.

No hay duda en el caso de los numerosos señoríos alaveses o en el del señorío de Oñate. Los señores, en sus distintos señoríos, mantenían habitualmente tierras en propiedad que cedían a los campesinos, disfrutaban de derechos sobre montes, pastos, etc. y percibían prestaciones en trabajo, censos y rentas de carácter territorial, jurisdiccional, las procedentes de los monopolios sobre los molinos e, incluso, las rentas reales correspondientes a cada una de las circunscripciones. El mosaico señorial alavés se reducía en Vizcaya a un solo señorío ${ }^{29}$ cuyo titular, a partir de 1379 , era el rey de Castilla que mantenía allí sus delegados - prestamero, merinos, con la incorporación posterior del corregidor y sus subalternos- y en cada una de las villas -preboste-, que administraban las rentas que percibía en el territorio. De entre estas destacan el pedido de los labradores censuarios, censo que pagaban los enfiteutas del señor de Vizcaya y cuya cantidad se había fosilizado en torno a 1436 en 100.000 mrs., sin duda, como señaló Emiliano Fernández de Pinedo, por el interés del señor en estimular la permanencia de los campesinos en las casas censuarias y evitar el constante abandono de las mismas ${ }^{30}$ que, como demuestran el Fuero Viejo y el Fuero Nuevo, abandonaban con facilidad para instalarse en tierras libres de censos. También son relevantes el pedido de las villas también tasado «según los preuilegios a las tales dados", los derechos de ferrerías "por lo seco de los montes, la mitad de la guarda del verde en los montes acostumbrados e sus seles» $y$, finalmente, «sus monesterios», es decir, los derechos decimales sobre las iglesias bajo su patronato. Un conjunto de rentas que subrayan el antiguo dominio señorial ${ }^{31}$, pero que, como sucede

27 García de Cortázar, José Ángel. «La creación de los perfiles físicos e institucionales del Señorío de Vizcaya en el siglo XIII". En Les Espagnes médiévales. Aspects économiques et sociaux. Mélanges offerts à Jean Gautier Dalché. Paris: Les Belles Lettres, 1983, pp. 1-11; García DE CorTázar, José Ángel. «El Señorío de Vizcaya». En Los orígenes del Principado de Asturias y de la Junta General. Oviedo, 1998, pp. 301-302. Para otros aspectos relacionados con la cuestión véase también el trabajo del mismo autor, «El Señorío de Vizcaya: personalidad y territorialidad en la estructura institucional de un señorío bajomedieval». En Poderes públicos en la Europa Medieval: principados, reinos y coronas. Pamplona: Gobierno de Navarra, 1997, pp. 117-148. Una síntesis para el conjunto del actual País Vasco en Dacosta, Arsenio. «El desarrollo de las instituciones de gobierno (siglos viII-Xv)». En Barruso y Lema (eds.), Historia del País Vasco, pp. 155-215.

28 Díaz de Durana, Álava en la Baja Edad Media, pp. 320 y ss.

29 A excepción hecha del valle de Villaverde de Trucíos, adquirido por los Velasco a los Avellaneda en 1440 (véase Dacosta, Los linajes de Bizkaia, pp. 134 y ss.).

30 Fernández de Pinedo, Emiliano. "¿Lucha de bandos o conflicto social?». En La sociedad vasca rural y urbana, p. 35. Estos labradores, cuyo origen se hunde en los siglos anteriores y distan de ser un grupo monolítico, merecen un estudio profundo aún sin realizar. Una aproximación al problema en GARCÍA DE Cortázar et álii, Vizcaya en la Edad Media, vol. III, pp. 299 y ss; y Otazu, Alfonso de y Díaz de Durana, José Ramón. El espíritu emprendedor de los vascos. Madrid: Sílex, 2008, pp. 83 y ss.

31 Bilbao, Luis María. "Haciendas forales y haciendas de la monarquía: el caso vasco, siglos XIV-XVI». En Historia de la Hacienda en España (siglos XVI-XX). Homenaje a Don Felipe Ruiz Martín. Madrid: Instituto 
JOSÉ RAMÓN DÍAZ DE DURANA Y ARSENIO DACOSTA

TITULARIDAD SEÑORIAL, EXPLOTACIÓN Y RENTAS DE LOS RECURSOS AGRÍCOLAS,

GANADEROS Y FORESTALES EN EL PAÍS VASCO AL FINAL DE LA EDAD MEDIA

en el caso de la que pagaban los campesinos censuarios, apenas tenían relevancia desde el punto de vista de la cantidad recaudada.

Particular mención merecen también en ese mismo sentido los patronatos sobre las iglesias que habían sido enajenados por el señor/rey a los linajes vizcaínos y guipuzcoanos. La titularidad de los derechos de patronato implicaba el ejercicio del derecho de presentación de los clérigos que servían el culto de la iglesia y la ocupación de un lugar preeminente en la iglesia tanto en vida, durante las celebraciones litúrgicas, como después de la muerte, en la tumba familiar colocada en el lado del Evangelio del altar mayor. Pero junto a estos elementos simbólicos, los derechos de patronato sobre las iglesias constituyeron una fuente de ingresos regular y segura para los parientes mayores: percibían los diezmos de los parroquianos y recaudaban las rentas de las tierras, seles, bosques y otros derechos sobre distintos bienes -molinos, ferrerías, etc.- que pudieran estar asociados a esas iglesias de patronato laico. El continuado ejercicio de esos derechos desde tiempo inmemorial, como pretende el alegato de los hidalgos frente a los obispos en las Cortes de Guadalajara de 1390 -atribuido a Pero López de Ayala-, puso en manos de los parientes un instrumento de control y dominación sobre los parroquianos y colaboró notablemente a construir, asentar y perpetuar su poder en los estrechos ámbitos territoriales de su influencia. Hasta tal punto que el citado alegato justifica la percepción de los diezmos, y por extensión el ejercicio de los derechos de patronato, «por razón del conosçimiento del señorío general $»^{32}$. Esta vinculación entre patronato y señorío explica perfectamente la alarma que despierta entre los cabezas de linaje el cuestionamiento de sus derechos por los obispos de Calahorra, Pamplona y Burgos en tiempos de Juan I y nos ofrece una prueba contundente de cómo los hidalgos y los hombres situados bajo su ámbito de influencia entendían esos derechos sobre los patronatos como una suerte de señorío. Señores sin señorío que, además de sus derechos sobre los patronatos, eran titulares de tierras que explotaban campesinos sometidos a censos y sobre los que en ocasiones, además, ejercían la justicia como cuando ostentaban los oficios de merino o trataban de apropiarse de la primera instancia judicial.

\footnotetext{
de Estudios Fiscales, 1991, pp. 43-58; Díaz de Durana, José Ramón y Piquero, Santiago. «Fiscalidad real, fiscalidad municipal y nacimiento de las haciendas provinciales en el País Vasco (ss. XIII-Xv)». En Menjot, Denis y Sánchez, Manuel (eds.). Fiscalidad de Estado y fiscalidad municipal en los reinos hispánicos medievales. Madrid: Casa de Velázquez, 2006, pp. 53-89.

32 «E, señor, a lo que dicen que estos diezmos tales non caen en persona de lego, dícennos los letrados que los diezmos son debidos a las iglesias por una de dos maneras: la una, por reverencia e acatamiento del servicio divinal que en ellas se faze, e tal diezmo como este, que es puro espiritual, non le puede aver lego, nin levar las tales rentas; la otra, por razón del conoscimiento del señorío general, e en este caso puede levar el lego los frutos dende; e este es el caso por do nosotros levamos los tales diezmos». En 1476 Lope García de Salazar introducirá al final de su Libro de las buenas andanças e fortunas un alegato aún más radical, con un fuerte carácter político. Sobre esto último, veáse: Villacorta, Consuelo. "Creando memoria: Pedro López de Ayala y Lope García de Salazar». En Fernández De Larrea, Jon Andoni y Díaz De Durana, José Ramón (coords.). Memoria e Historia. Utilización política en la Corona de Castilla al final de la Edad Media. Madrid: Sílex, 2010, pp. 68 y ss. Sobre ambos testimonios, Dacosta, Arsenio. «De la conciencia del linaje a la defensa estamental. Acerca de algunas narrativas nobiliarias vascas». Medievalista online, 2010, vol. 8, pp. 40 y ss.
} 
JOSÉ RAMÓN DÍAZ DE DURANA Y ARSENIO DACOSTA

TITULARIDAD SEÑORIAL, EXPLOTACIÓN Y RENTAS DE LOS RECURSOS AGRÍCOLAS,

GANADEROS Y FORESTALES EN EL PAÍS VASCO AL FINAL DE LA EDAD MEDIA

La CONTABILIdad del SEÑor. El SEÑorío de doÑa Blanca y doÑa LeONOR de Mendoza Sobre las aldeas de los Huetos y Mártioda

Como primer ejemplo de nuestro estudio abordaremos el que puede considerarse un prototipo de gestión de un pequeño señorío rural. Lo hacemos gracias a varios documentos inéditos depositados en el Archivo de la Real Chancillería de Valladolid que registran la «contabilidad» del mayordomo de dońa Blanca y dońa Leonor de Mendoza sobre las aldeas de los Huetos -Hueto de Suso y Hueto de Yuso- y Mártioda durante los años 1404 a 1412, 1422 y 1425 a 1428. Se incluye información, además, de diversas rentas en los lugares de Estavillo y Rivabellosa para los ańos 1405 y 1406. Conocemos los ingresos en cada una de las aldeas y por cada uno de los distintos conceptos: tributos de reconocimiento señorial, censos en especie y en dinero sobre distintos bienes, derechos derivados de la justicia, diezmos de las iglesias de distintos lugares, mercedes reales, etc. Y también, para los tres primeros años, los conceptos y las cantidades en los que se gastan, dedicados en su mayoría al «mantenimiento de las doncellas»"33.

El dominio señorial de los Mendoza sobre las aldeas de los Huetos y otros territorios cercanos era anterior, pero su señorío sobre ambas se inició formalmente el 2 de abril de 1332, cuando Alfonso XI concedió a Juan Hurtado de Mendoza, en pago a los servicios prestados durante su misión ante el rey de Inglaterra, los pechos y derechos sobre ambos lugares $^{34}$. Apenas diez ańos más tarde, le entregó la jurisdicción sobre ambas aldeas ${ }^{35}$. Fue el primer señorío que se otorgó en Álava después que los cofrades de la Junta de Arriaga entregaran al rey la jurisdicción sobre las tierras de la Cofradía. Se inició entonces una cadena de mercedes que terminó con el paso de la mayoría de las tierras alavesas del realengo al señorío.

Blanca y Leonor disfrutaron de las rentas y derechos sobre ambas aldeas a partir de la muerte de su padre, Ruy Díaz de Mendoza, fundador de la rama mendocina

33 La «contabilidad" se ha conservado como una prueba - probablemente para demostrar la antigua titularidad seńorial sobre esas aldeas- en un pleito entre los vecinos de las aldeas de los Huetos y su señor, Luis de Mendoza, en torno al nombramiento de oficiales de ambos concejos. En ningún momento a lo largo del pleito se hace referencia a la "Cuenta que Pero Ortis de Urbina, alcayde de la casa de Mártioda» entregó a su seńora. En este momento trabajamos en la edición de los documentos relacionados con la contabilidad de este señorío laico que publicaremos durante el próximo ańo junto a un estudio más extenso sobre la información allí registrada. Archivo Real Chancillería de Valladolid (en adelante ARChVa), Pleitos Civiles, Quevedo, Fenecidos, C 2594/2, leg. 564.

34 "Don Alonso por la graçia de Dios rey de Castilla, [...] por hazer bien y merçed a vos Juan Hurtado de Mendoça mi vasallo por muchos serviçios que me fezistes y me fazéys, do vos que ayades por juro de heredad los pechos y derechos de dos aldeas que son en Álava que dizen a la una Hueto de Susso y a la otra Hueto de Yuso en que ayades de ellos el pan del semoyo y el buey de março [...] con todos los otros derechos dende, por juro de heredad para vos y para los que después de vos vinieren y lo ovieren de aver» (1332, abril 2. Burgos. Archivo Municipal de Villanueva de Valdegovía, s/s; 1526).

35 «Porque nos tubimos por bien de fazer merçed a Juan Furtado de Mendoça nuestro vasallo en que le dimos [...] Hueto de Suso y a Hueto de Yuso [...] con los pechos y derechos e con el pan del semoyo y el buey de março y retubimos en nos la nuestra justiçia y el sennorío real, e agora el dicho Juan Furtado pidionos por merçed que le diésemos la justiçia de las dichas aldeas porque él oviesse el sennorío de ellas cumplidamente, e nos por hazer bien y merçed al dicho Juan Furtado por muchos serviçios que nos fizo y nos faze [...] dámosle que aya las justiçias de las dichas aldeas [...] e retenemos en nos la justiçia si la menguare [...] e las alçadas» (1342, enero, 8. Valladolid. A. M. Villanueva de Valdegovía, s/s; 1526). 
JOSÉ RAMÓN DÍAZ DE DURANA Y ARSENIO DACOSTA

TITULARIDAD SEÑORIAL, EXPLOTACIÓN Y RENTAS DE LOS RECURSOS AGRÍCOLAS, GANADEROS Y FORESTALES EN EL PAÍS VASCO AL FINAL DE LA EDAD MEDIA

de Mártioda, en $1404^{36}$. Una atenta lectura de las cuentas del mayordomo de las doncellas -resumida en los Cuadros 1, 2 y 3- evidencia cómo los ingresos procedían, en primer lugar, de tributos en reconocimiento de señorío como el semoyo, el buey de marzo, la martiniega o el servicio. Los dos primeros formaban parte del llamado pecho forero que los campesinos de las tierras de la Cofradía de Arriaga pagaban a los hidalgos en reconocimiento de señorío y que, desde 1332, continuaron pagando a Juan Hurtado de Mendoza y sus sucesores. El semoyo lo pagaban en especie -una fanega y media, mitad trigo y mitad cebada- los pecheros avecindados en la aldea ${ }^{37}$. El buey de marzo debió ser una marzazga que inicialmente se pagó en especie y, más tarde, se monetarizó ${ }^{38}$. El pecho de San Martín era una martiniega, una cantidad - probablemente tasada- que se pagaba en dinero ${ }^{39}$. Finalmente, el servicio, como los anteriores, parece tener el sentido de una «obligación debida» al señor, aunque desconozcamos en este caso sus características ${ }^{40}$.

36 Ambas damas son desconocidas para la historiografía que se ha ocupado de los Mendoza, que ha señalado a María de Mendoza como heredera de Ruy Díaz de Mendoza. María de Mendoza, casada con Diego Pérez Sarmiento, repostero mayor del rey, ya había enviudado en 1441 (Portilla, Micaela Josefa. Las torres de Mendoza y Mártioda. Vitoria: Diputación Foral de Álava, 1985, pp. 48-52). La última señora de Mártioda, rama secundaria de los Hurtado de Mendoza, doña María Josefa de Urdaibay y Hurtado de Mendoza, morirá en 1847. Agradecemos a Juan Vidal-Abarca sus valiosas informaciones al respecto.

37 Los hidalgos no pagaban el pecho forero. En tierras de Valdegovía, al suroeste de Álava, en 1526, se pagaba del siguiente modo: «el vecino que tuviere yugada de bueyes o mulas, o de ahí arriba, quince celemines de pan la mitad de trigo e la mitad cebada de la medida de Ávila y el que tuviere media yugada la mitad y el que sembrare sin tener yugada pague la quarta parte conforme es costumbre en la provincia de Álava, la qual se ha de pagar por fin de septiembre» (A. M. Villanueva de Valdegovía, s/s; 1526).

38 Díaz de Durana, José Ramón. "Fiscalidad real en Álava durante la Edad Media». En Fernández De Pinedo, Emiliano (ed.). Haciendas forales y Hacienda real. Homenaje a D. Miguel Artola y D. Felipe Ruiz Martín. Bilbao: Universidad del País Vasco, 1990, p. 151.

39 En algunos lugares, el semoyo y el buey de marzo se englobaban o se confundían con la martiniega. De hecho, en las aldeas de algunas hermandades, como Zuya o Cigoitia, se asociaban con el pecho de San Martín que pagaban a los señores de la tierra, los Avendaño. ARChVa, Pleitos Civiles, Zarandona y Balboa, leg. 711/1. Así, mientras que en Valdegovía el semoyo se pagaba en septiembre, en otros su pago se había retrasado a noviembre, asociándose a la martiniega quizá para que no quedara ninguna duda sobre el debido reconocimiento de señorío. El buey de marzo, aunque no tenemos noticia concreta, se pagaba probablemente en el mes que le da nombre. El mayordomo recaudaba también el pecho de San Martín en Estavillo y Rivabellosa.

40 Martínez Sopena, Pascual. «Poder, servicio y renta». En Señores, siervos, vasallos en la Alta Edad Media. XXVIII Semana de Estudios Medievales de Estella. Pamplona: Gobierno de Navarra, 2002, pp. 183-217. 
JOSÉ RAMÓN DÍAZ DE DURANA Y ARSENIO DACOSTA

TITULARIDAD SEÑORIAL, EXPLOTACIÓN Y RENTAS DE LOS RECURSOS AGRÍCOLAS,

GANADEROS Y FORESTALES EN EL PAÍS VASCO AL FINAL DE LA EDAD MEDIA

Cuadro 1.- Ingresos en Hueto de Suso y de Yuso (1404-1412).

\begin{tabular}{|c|c|c|c|c|c|c|c|c|c|c|c|c|c|c|}
\hline & & 1404 & 1405 & 1406 & $1407 / 8$ & 1409 & 1410 & 1411 & 1412 & 1422 & 1425 & 1426 & 1427 & 1428 \\
\hline Pecho de San Martín ${ }^{1}$ & & & 3.500 & 3.500 & 3.500 & 3.500 & 3.500 & 3.500 & 3.500 & 3.500 & 3.500 & 3.500 & 3.500 & 3.500 \\
\hline Buey de marzo & & & 60 & 60 & 60 & 60 & 60 & 60 & 60 & 60 & 60 & 60 & 60 & 60 \\
\hline Carneros & & & 26,4 & 26,4 & 26,4 & 26,4 & 26,4 & 26,4 & 26,4 & 26,4 & 26,4 & 26,4 & 26,4 & 26,4 \\
\hline Servicio f.t & & & 20 & 20 & 20 & 20 & 20 & 20 & 20 & 20 & 20 & 20 & 20 & 20 \\
\hline \multirow[t]{2}{*}{ Heredad Urrialdo } & $\mathrm{Ft}$ & & 15 & 15 & 15 & 15 & 15 & 15 & 15 & 15 & 15 & 15 & 15 & 15 \\
\hline & $\mathrm{Fc}$ & & 15 & 15 & 15 & 15 & 15 & 15 & 15 & 15 & 15 & 15 & 15 & 15 \\
\hline \multirow[t]{2}{*}{ Parral Herraynas } & $\mathrm{Ft}$ & & 7 & 7 & 7 & 7 & 7 & 7 & 7 & 7 & 7 & 7 & 7 & 7 \\
\hline & $\mathrm{Fc}$ & & 7 & 7 & 7 & 7 & 7 & 7 & 7 & 7 & 7 & 7 & 7 & 7 \\
\hline \multirow[t]{2}{*}{ Semoyo $^{2}$} & $\mathrm{Ft}$ & & 18,9 & 15,9 & 39,3 & 21,7 & 16,5 & & 18,5 & $14 \frac{1}{4}$ & 13,5 & 13 & 14,3 & 15,5 \\
\hline & $\mathrm{Fc}$ & & 18,9 & 15,9 & 39,3 & 21,7 & 16,5 & & 18,5 & $14^{1 / 4}$ & 13,5 & $13^{3}$ & $14,3^{4}$ & 15,5 \\
\hline \multirow[t]{2}{*}{ Renta Collazos } & $\mathrm{Ft}$ & 5,5 & 5 & 5,5 & 7 & $2^{5}$ & 2 & 2 & 2 & 2 & 2 & 2 & 2 & 4 \\
\hline & $\mathrm{Fc}$ & $5,5^{6}$ & 5 & 5,5 & 7 & 2 & 2 & 2 & 2 & 2 & 2 & 2 & 2 & $4^{7}$ \\
\hline Pieza & & $11 \mathrm{fc}^{8}$ & baldia & $9,2 \mathrm{ft}$ & $6 \mathrm{fc}^{9}$ & $6 \mathrm{ft}^{10}$ & $6 \mathrm{ft}$ & baldia & $8 \mathrm{ft}$ & & & & & \\
\hline Alcaldía & mrs. & & $230^{11}$ & 230 & & & & & & & & & & \\
\hline
\end{tabular}

Maravedís expresados siempre en moneda vieja.

"Pagaron más dies e nueve semoyos que ovo en Hueto de yuso e seys semoyos que ovo en Hueto de suso fanega e media por semoyo".

18 semoyos.

«Dies e nuebe semoyos, que este anno pujó un labrador».

Entre 1409 y 1427 únicamente paga un collazo.

6 "En Hueto de yuso pagó un collaço dos fs. de to e dos de ç; en Hueto de suso pagan dos collaços tres fs. de tº e tres de ç; pagan más dos filanderas çinco çls. de trigo e çinco de ç».

"Otrosý mi sennora fiso merçed a Pedro de Estarrona, collaço, que fuese libre de la collaçía e a de pagar en estos dies annos cada anno ocho fanegas de pan; asý pagó este anno las dichas ocho fanegas de pan».

8 «Rendió más una pieça que es de las dichas donsellas que la an de labrar el conçejo e coger el pan a su costa e las donsellas que dan la simiente e un anno es trigo en otro çebada en otro fuelga. Ovo este anno en ella quita la simiente e diesmo».

9 «Los besinos de Hueto e Hueto de las rrentas de la pieça de la torre que ovieron de la dicha pieça en el año de mill quatroçientos e siete annos seys fanegas de çebada e en el otabo yagó baldía e non rentó cosa».

10 "Pieça de la Torre de Hueto este anno sobredicho, pagada la simiente que en ella pus y e sacado el diesmo».

11 "An más las dichas donsellas de derecho en las dichas aldeas dosientos e treynta mrs. de moneda vieja del alcallía. Estos liévalos el alcaille por su alcallía». 
JOSÉ RAMÓN DÍAZ DE DURANA Y ARSENIO DACOSTA

TITULARIDAD SEÑORIAL, EXPLOTACIÓN Y RENTAS DE LOS RECURSOS AGRÍCOLAS,

GANADEROS Y FORESTALES EN EL PAÍS VASCO AL FINAL DE LA EDAD MEDIA

CuAdro 2.- Ingresos en Mártioda (1404-1428).

\begin{tabular}{|c|c|c|c|c|c|c|c|c|c|c|c|c|c|c|}
\hline & & 1404 & 1405 & 1406 & $1407 / 8$ & 1409 & 1410 & 1411 & 1412 & 1422 & 1425 & 1426 & 1427 & 1428 \\
\hline \multirow[t]{2}{*}{ Diezmo del monasterio ${ }^{1}$} & $\mathrm{Ft}$ & 31,7 & 49,8 & 52,8 & & & & & & & & & & \\
\hline & $\mathrm{Fc}$ & $20,7^{2}$ & $22,3^{3}$ & 37,4 & & & & & & & & & & \\
\hline \multirow[t]{2}{*}{ Diezmo del monasterio ${ }^{4}$} & $\mathrm{Ft}$ & & & & & & & & & & 8 & 11 & 6 & 6 \\
\hline & $\mathrm{Fc}$ & & & & & & & & & & 8 & 11 & $6^{5}$ & 6 \\
\hline Pie de altar / Menuçias & $\mathrm{Ft}$ & $\ldots--^{6}$ & $20 \mathrm{ft}^{7}$ & $20 \mathrm{ft}$ & & & & & & & & & & \\
\hline Yantar $^{8}$ & Mrs. & $100^{9}$ & 100 & 100 & & & & & & & & & & \\
\hline \multirow[t]{2}{*}{ Heredades / Casas } & $\mathrm{Ft}$ & & & 20 & & & & & & & & & & \\
\hline & $\mathrm{Fc}$ & & & 20 & & & & & & & & & & \\
\hline \multirow[t]{2}{*}{ Total } & & $5,7 \mathrm{ft}$ & $47,8 \mathrm{ft}$ & & & & & & $50 \mathrm{ft}$ & & & & & \\
\hline & & $8,7 \mathrm{fc}^{10}$ & $20,3 \mathrm{fc}^{11}$ & $43,7 \mathrm{f}$ & $120,1 \mathrm{f}^{12}$ & $60 \mathrm{f}^{13}$ & $15 \mathrm{f} 3 / 4^{14}$ & $3 f^{3} 3 / 4 c^{15}$ & $25 \mathrm{fc}^{16}$ & & & & & \\
\hline
\end{tabular}

1 Iglesia parroquial de Mártioda.

2 «El diesmo del monesterio de la dicha aldea montó este anno el diesmo de la dicha iglesia e el quarto de lo que se coje en las herrays que son de las doncellas".

3 «Ovo de diesmo en el monesterio de la dicha aldea que es de las dichas donsellas e el quarto de las herrays que pertenesçen a ellas setenta e una fanega e to xlix fs. viii çls.».

Monasterio de San Vicente de Quartango.

5 «Ete anno abaxó la renta».

6 «An más las dichas donsellas el pie de altar de la dicha eglesia e menuçias e obladas. Et levolo este anno el alcayde por retenençia de la torre demás del trigo e dineros suso escripto".

«An más del pie de altar del dicho monesterio e del diesmo de la menuçia de todo lo que perteneçe a la eglesia demás del trigo e ç sobredicho esto solía aver el alcayde por retenençia de la torre demás de veynte e quatro fanegas de trigo que avía de retenençia e fuele quitado este diesmo e menuçia por carta de Juan Furtado, tutor que fue de las dichas doncellas, e que non oviese por la dicha retenençia e pan salvo las dichas veynte e quatro fanegas de trigo. E porque el dicho alcayde resçibió dicho diesmo e menuçia este anno paga por ello».

8 Maravedís expresados siempre en moneda vieja.

9 "Pagan mas de yantar la dicha aldea este dicho anno çient mrs. de yantar. Estos ovo el alcayde por retenençia de la torre».

10 «Suma este pan desta aldea de Mártioda deste dicho anno quarenta e siete fs. e syete çls. de to e treynta e seys fs. e syete çls. de ç. Desto son de destomar de la capellanía del dicho monesterio deste dicho anno dies e ocho fs. de $t^{0}$ e dies e ocho fs. de ç e al alcyde por la retenençia de la torre desta dicha aldea veynte e quatro fs. de $\mathrm{t}^{\mathrm{o}} \%$.

11 «Suma este pan de Mártioda çiento e veynte e tres fanegas e honse çelemines en esta guisa: ochenta e çinco fanegas e ocho çls. de trigo e treynta e ocho fanegas e tres çls. de ç. Desto es de descontar de la capellanía de dicho monesterio dies e ocho de ç e veynte e quatro fgs. de trigo que ovo el dicho alcayde por retenençia de la torre».

12 «Asý suma trigo e çebada de los dos annos de Mártioda çient e nobenta e dos fanegas e un çelemín asý alcançadas (?) setenta e dos fanegas de capelanía de los dichos dos annos finca que devo yo, Pero Urtis, çient e veynte fanegas e un çelemín».

13 «Asý suma el resçibo del trigo del anno de mill e quatroçientos e nuebe annos cinquenta fanegas e nueve çelemines de trigo e de çebada quarenta e cinco fanegas e tres çelemines. Asý suma por todo este resçibo de Mártioda del dicho anno nobenta e seys fanegas de trigo e çebada. Sacadas treinta e seys fanegas de capellanía, finca en mí, Pero Urtis, sesenta fanegas».

14 «Suma el resçibo deste trigo deste dicho anno de las rrentas de Mártioda sesenta e dos fanegas e tres çelemines de trigo lxii fs. iii çls. de trigo. Más treinta e tres fanegas e nuebe çelemines de çebada xxxiii fs. e ix çls ç. Asý, sacadas dis e ocho fanegas de capellanía, fincan en mí quarenta e çinco fanegas de trigo e tres quartas. Sacadas dis e ocho fanegas del capellán, fincan en mí quince fanegas e tres quartas de çebada».

15 «Diesmos e quartos e botijas. Suma el trigo sesenta e siete fanegas lxvii fs. trigo. Suma la çebada veynte e una fanega e tres quartas xxi fs. iii quartas ç. Pagado el capellán de dis e ocho fanegas de trigo, fincan quarenta e nueve fanegas de trigo. Pagado el capellan de dis e ocho fanegas de çebada, fincan tres fanegas e tres quartas de çebada».

16 «Rrentas e diesmos e botijas e quartos. Suma el trigo sesenta e sesys fanegas e quarenta e tres fanegas de çebada. Sacado el capellán fincan çinquenta fanegas de trigo e veynte çinco fanegas de çebada». 
JOSÉ RAMÓN DÍAZ DE DURANA Y ARSENIO DACOSTA

TITULARIDAD SEÑORIAL, EXPLOTACIÓN Y RENTAS DE LOS RECURSOS AGRÍCOLAS,

GANADEROS Y FORESTALES EN EL PAÍS VASCO AL FINAL DE LA EDAD MEDIA

Cuadro 3.- Ingresos en Estavillo y Rivabellosa (1405-1406).

\begin{tabular}{|c|c|c|c|}
\hline & & $1405^{1}$ & 1406 \\
\hline \multirow[t]{3}{*}{ Estavillo } & Pecho de San Martín & $3.000 \mathrm{mrs}$. & $3.000 \mathrm{mrs}$. \\
\hline & Parrales & $\begin{array}{c}50 \text { cántaras de vino }{ }^{2}=646 \\
\text { mrs. }\end{array}$ & 230 cántaras de vino ${ }^{3}=3.200 \mathrm{mrs}$. \\
\hline & Molino ${ }^{4}$ & & $30 \mathrm{ft}$ \\
\hline \multirow[t]{3}{*}{ Rivabellosa } & Pecho de San Martín & $1.005 \mathrm{mrs}$ & $1.005 \mathrm{mrs}$. \\
\hline & Buey de marzo & $30 \mathrm{mrs}$. & $30 \mathrm{mrs}$. \\
\hline & Semoyo y filandera & $\begin{array}{l}3 \mathrm{f} \text { y } 11 \text { celemines trigo } \\
3 \mathrm{f} \mathrm{y} 11 \text { celemines cebada }\end{array}$ & $\begin{array}{l}3 \text { f y } 11 \text { celemines trigo } \\
3 \text { f y } 11 \text { celemines cebada }\end{array}$ \\
\hline
\end{tabular}

Las cantidades en maravedís lo son de moneda vieja para ambos ańos.

«Cinquenta cántaras de vino; que non ovo más por quanto apedreó. Deste dicho vino vendieron el conçejo treynta e ocho cántaras a dies e syete mrs. E estos dichos mrs. e dose cántaras de vino que fincan espendieron en la labor de los parrales deste dicho anno. Et más espendieron en la de los dichos parrales deste dicho anno de los dichos tres mill mrs. que aváan a dar del dicho pecho dosientos e sesenta e quatro mrs. de moneda vieja. Así que pagaron en dinero para complimiento de todo esto sobredicho dos mill e seteçientos e treynta e seys mrs. de moneda vieja».

230 cántaras de vino a $14 \mathrm{mrs}$. la cántara, $3.200 \mathrm{mrs}$. Debe descontarse la vendimia que no se especifica como el año anterior.

Por un año, de San Juan a San Juan. En años anteriores estaba desbaratada.

"An más de semoyo con una filandera çinco semoyos e quatro çls. de una filandera cada semoyo fanega e media de pan la mª trigo e la mitad çebada que son syete fanegas e dies celemines la meytat to la mitat çebada».

En segundo lugar, las doncellas, como patronas de la iglesia parroquial de Mártioda, ingresaban los diezmos, el pie de altar y las menucias correspondientes a la misma que representaban la parte del león de los ingresos en esa aldea. Al menos desde 1425, cobraban también los diezmos del «monasterio» de San Vicente de Cuartango.

En tercer lugar, el mayordomo de las doncellas recaudaba censos en especie por distintos conceptos. Tres collazos -campesinos dependientes que trabajan las tierras del señor- pagaban una cantidad probablemente en razón de la casa que habitaban y de las tierras que cultivaban. Cinco vecinos de Mártioda pagaban en 1405 otra cantidad denominada botija en razón de la casa que habitaban:

Pagaron más de botijas este dicho anno dies e seys fs. de trigo e dies e seys fs. de çebada en esta guisa: Juan Abad por la casa que es del sennor tres fanegas de $t^{0} \mathrm{e}$ tres fs. de ç. Pero Ruys su hermano, por otra casa tres fs. de to e tres fs ç. Juan de Palaçio por otra casa tres fs. de $\mathrm{t}^{\mathrm{o}} \mathrm{e}$ tres fs. ç. Juan Ortis por otra casa tres fs. de to e tres fs. ç. Juan de Mendoça por un palaçio. una fga. de trigo e otra de ç.

Las referencias a la botija ${ }^{41}$ la relacionan siempre con campesinos dependientes o con malos usos, como en el Fuero de Nájera ${ }^{42}$. También en Mártioda, las doncellas

41 Sobre la botija contamos con algunas informaciones sobre la Baja Navarra -CiERBIDE, Ricardo (ed.). Censos de población de la Baja Navarra (1350-1353 y 1412). Tübingen: Max Niemeyer Verlag, 1993-. También está documentada en Álava a principios del siglo XIV (PAz Moro, El monasterio de Barría, doc. 11.

42 "Et si compraverit homo de Nagara in villio hereditates, terras, vineas aut quamcumque hereditatem, Samper habeat illa sine ullo malo fuero et sine botilla». 
JOSÉ RAMÓN DÍAZ DE DURANA Y ARSENIO DACOSTA

TITULARIDAD SEÑORIAL, EXPLOTACIÓN Y RENTAS DE LOS RECURSOS AGRÍCOLAS, GANADEROS Y FORESTALES EN EL PAÍS VASCO AL FINAL DE LA EDAD MEDIA

percibían censos por 26 heredades y cinco sernas, así como las rentas correspondientes a ocho vecinos ${ }^{43}$. Finalmente otra cantidad más en especie -inferior a media fanega de pan- es denominada filandera. En una ocasión se cita en referencia a lo que parecen ser dos mujeres que desarrollan una actividad textil y pagan esa cantidad en pan ${ }^{44}$. Además recaudaba otros censos en dinero. Particularmente dos, el de los carneros, procedente de un tributo que en una etapa anterior pagaban en especie, y el yantar, debido a las señoras.

El mayordomo, finalmente, gestionaba también los ingresos procedentes de varias propiedades de las doncellas en distintas aldeas. Destacan por su cuantía una pieza en Hueto - «que es de las dichas donsellas que la an de labrar el conçejo e coger el pan a su costa e las donsellas que dan la simiente e un anno es trigo en otro çebada en otro fuelga»-, la heredad de Urrialdo - un despoblado cercano a los Huetos-, los parrales de Hueto y Estavillo, la casa de Mendoza y, desde 1405, un molino en Estavillo.

En definitiva, un conjunto de ingresos procedentes en su mayoría de los derechos jurisdiccionales, de la explotación de distintos bienes y de las rentas derivadas de los mismos conforman la columna vertebral de los ingresos de los Mendoza de Mártioda en las aldeas de referencia. En su estructura, son similares a la de otros grandes seńoríos cercanos $^{45}$. Hay similitudes - porcentajes elevados de ingresos en especie- y también notables diferencias, en particular el hecho de que en otros seńoríos -por ejemplo en las hermandades del duque del Infantado- se incorporan a los ingresos cantidades en dinero relevantes procedentes de rentas reales -alcabala-, apenas compensadas en el caso de nuestras doncellas por una merced real de 5.000 maravedís a la muerte de su padre $^{46}$. Como en otros casos, no hay rastro de la explotación señorial directa y en sus ingresos predominan las rentas seńoriales arcaicas fosilizadas durante el periodo observado.

El texto «contable» registra una importante novedad: junto a los ingresos procedentes de los lugares señalados, el mayordomo anotó también los gastos atribuidos al mantenimiento

43 «La casa de Landaburu debe de renta seys fanegas misto. La casa de Juan de Ascoa debe de renta seys fanegas misto. La casa de Ochoa debe de renta seys fanegas misto. La casa de Sancho debe de renta seys fanegas misto. La casa de Mariochoa debe de renta seys fanegas misto. La casa de Martín Ferrandes debe de renta iiii fanegas misto. La casa de Juan hijo de Ochoa debe de renta ii fanegas misto. La casa de Mari Mendoça debe de renta iiii fanegas misto".

44 "Más dos filanderas çinco çls. de trigo e çinco de ç.». En otra ocasión se cita del siguiente modo: "An más de semoyo con una filandera çinco semoyos e quatro çls. de una hilandera». Un texto de Ońa puede interpretarse también en ese mismo sentido. En 1237, el abad va desgranando las cantidades que deben los campesinos de La Nuez, a quienes ha rebajado el número de sernas, hasta llegar a «la filandera de nos kada un anno, medio almud de pan, la una quarta de trigo e la otra de ordio, e tres dineros». Carta de don Miguel, abad de Oña (documento publicado por Álamo, Juan del. Colección diplomática de San Salvador de Oña. Madrid: CSIC, 1950, tomo II, p. 594; consultado en el banco de datos CORDE (Corpus diacrónico del español: <http://corpus.rae.es> [5/3/2014]). Utiliza el texto Álvarez Borge, Ignacio. "Dependencia campesina, propiedad de los señores y señoríos en Castilla la Vieja en la Plena Edad Media». Historia Agraria, 1999, vol. 19, pp. 9-41.

45 Díaz de Durana, Álava en la Baja Edad Media, pp. 308-310.

46 El importe de las alcabalas que el duque llegó a percibir en sus hermandades alavesas se situó en 1537 en torno a 300.000 mrs. anuales, el 60\% de sus ingresos. Díaz de Durana, Álava en la Baja Edad Media, p. 309. El mayordomo de las doncellas registró así la merced real: «An más de merçet del rey para su mantenimiento çinco mill mrs. del rey. Destos les quitan dosientos e çinquenta de chançellería e veynte e seys mrs. de escribanos de tesorero e recabdador quatro mill e seteçientos e veynte e quatro mrs. de moneda blanca». 
JOSÉ RAMÓN DÍAZ DE DURANA Y ARSENIO DACOSTA

TITULARIDAD SEÑORIAL, EXPLOTACIÓN Y RENTAS DE LOS RECURSOS AGRÍCOLAS,

GANADEROS Y FORESTALES EN EL PAÍS VASCO AL FINAL DE LA EDAD MEDIA

de Blanca y Leonor desde la muerte de su padre el 25 de agosto de 1404 hasta finales de diciembre de 1406 -Cuadro 4-. Las anotaciones no se refieren solo a las doncellas, incorporan también dos mujeres de servicio y un mozo de mulas. Se asignan para su manutención cantidades en dinero dedicadas a "carne e pescado para las sobredichas, cada día ocho mrs. de moneda blanca» o al "vino para las sobredichas: açumbre e medio cada día», y se asientan las cantidades correspondientes a las compras de pańos y calzado destinados para las doncellas y su personal de servicio ${ }^{47}$.

CuAdro 4.- Gastos mantenimiento de las doncellas (1404-1406) ${ }^{48}$.

\begin{tabular}{|l|c|c|c|}
\hline & 1404 & 1405 & 1406 \\
\hline Trigo (ft) & 12 & 36 & 36 \\
\hline Carne e pescado (mrs.) ${ }^{49}$ & 1.000 & 2.928 & 2.928 \\
\hline Vino (mrs.) $^{50}$ & 280 & 823,5 & 1.098 \\
\hline Dos mulas (fc) & 51 & 91,3 & 91,3 \\
\hline Tejidos (mrs.) & $750^{52}$ & $6.400^{53}$ & $3.740^{54}$ \\
\hline Zapatos (mrs.) & & 48 & 48 \\
\hline 1 mula (mrs.) & 1.500 & & \\
\hline Total ft & 12 & 36 & 36 \\
\hline Total fc & 30 & 91,3 & 91,3 \\
\hline Total mrs. & 3.530 & 9.376 & 7.841 \\
\hline
\end{tabular}

En general, como puede apreciarse a través de los cuadros de referencia, no hay grandes diferencias en los ingresos anuales. Los ingresos en dinero y buena parte de los registrados en especie estaban fosilizados. Aunque los ańos en los que se han conservado los datos correspondientes a cada uno de los conceptos son los de 1404 -incompleto-, 1405 y 1406, puede afirmarse que a lo largo del periodo observado no hay grandes oscilaciones salvo aquellas debidas a la organización de la producción en los campos, el descenso del número de collazos que contribuyen o reducciones y/o condonaciones de

47 «Una aljuba e un manto de escarlata a meitat con mosterviller en penna gris», "dies varas de ypre para la muger que las sirve», "panno para el moço de sus mulas».

48 Gastos expresados en maravedís de moneda blanca o nueva. Los gastos corresponden a las dos doncellas, dos mujeres de servicio y un mozo de mulas.

49 "Carne e pescado para las sobredichas cada día ocho mrs. de moneda balnca».

50 "Vino para las sobredichas açumbre e medio cada día».

51 «Dos mulas suyas çelemín e $\mathrm{m}^{\circ}$ de ç cada noche a cada una para cada noche».

52 «Sendos pares de pannos de panno prieto para las dichas doncellas».

53 "Una opa e una mantellina de rrixa et bruneta en Pennavera», «una aljuba e un manto de escarlata ameitat con mosterviller en penna gris», "dies varas de ypre para la muger que las sirve», "panno para el moço de sus mulas".

54 "Una aljuba e un manto de Londres rroxo aforrado en çendal», "dos mantones de cavalgar e un capirote de mosterviller», «una aljuba e un manto de Londres verde con penna blanca». 
JOSÉ RAMÓN DÍAZ DE DURANA Y ARSENIO DACOSTA

TITULARIDAD SEÑORIAL, EXPLOTACIÓN Y RENTAS DE LOS RECURSOS AGRÍCOLAS, GANADEROS Y FORESTALES EN EL PAÍS VASCO AL FINAL DE LA EDAD MEDIA

censos. En el Cuadro 5 intentamos resumir para los años 1404-1406 los ingresos y gastos registrados por el mayordomo. En él ya están deducidas las cantidades entregadas al tutor de las doncellas, al alcayde de la fortaleza de los Huetos, así como el pago del diezmo y el coste de los obreros que acudían a la vendimia a recoger la uva de los "parrales». No resulta fácil valorar el total de ingresos -entre 20.000 y 25.000 maravedís anuales-, y compararlo con el de otros señoríos laicos o eclesiásticos alaveses citados anteriormente. Se trata de un espacio más reducido -apenas tres aldeas-, pero la fosilización de las rentas percibidas y su arcaísmo sugieren, sin embargo, cierta modestia en los ingresos que, en todo caso, resultaban más que suficientes tanto para mantener la estructura básica del señorío sobre las aldeas -torres de Mártioda y los Huetos, alcayde, etc.- como para la manutención de las dos doncellas y su reducido grupo de sirvientes. El saldo final permite comprobar cómo los gastos dedicados a Blanca y Leonor se sitúan entre el 40-45\% de los ingresos. El resto terminaba, sin duda, en el mercado de la cercana villa de Vitoria.

Cuadro 5.- Ingresos y gastos registrados por el mayordomo (1404-1406) ${ }^{55}$.

\begin{tabular}{|l|r|r|r|l|l|}
\hline & \multicolumn{1}{|c|}{ Ingresos } & \multicolumn{1}{c|}{$\%$} & Gastos & Saldo & $\%$ \\
\hline 1404 & & & & & \\
\hline Moneda vieja & $13.718,80$ & 79,96 & & & \\
\hline Moneda nueva & $1.543,50$ & 9,00 & & & \\
\hline Total moneda & $15.262,30$ & 88,95 & $3.530,00$ & & \\
\hline Trigo & $1.380,38$ & 8,05 & 243,00 & & \\
\hline Cebada & 514,71 & 3,00 & 245,10 & & \\
\hline Total & $17.157,39$ & & $4.018,10$ & $13.139,29$ & \\
\hline & & & & & \\
\hline 1405 & & & & & \\
\hline Moneda vieja & $13.422,60$ & 56,23 & & & \\
\hline Moneda nueva & $8.975,00$ & 37,60 & & & \\
\hline Total moneda & $22.397,60$ & 93,82 & $9.376,00$ & & \\
\hline
\end{tabular}

55 Los ingresos en dinero, que la contabilidad proporciona en moneda nueva y vieja, se han convertido en moneda nueva a partir de la equivalencia de un maravedí «viejo» por dos «nuevos». Los ingresos en especie se han monetizado con el promedio de los precios en Burgos de 1402 y 1406 en el caso del trigo y, para la cebada, también 1407, los únicos disponibles. Véanse: MacKaY, Angus. Moneda, precios y política en la Castilla del siglo XV. Granada: Universidad de Granada/Universidad de Sevilla, 2006, pp. 78-79; CaSAdo, Hilario. Señores, mercaderes y campesinos. La comarca de Burgos a fines de la Edad Media. Valladolid: Junta de Castilla y León, 1987, p. 287. Dada la estabilidad del maravedí en esta década (Mackay, Moneda, precios y política, p. 185; Casado, Hilario. «Producción agraria, precios y coyuntura económica en las diócesis de Burgos y Palencia a fines de la Edad Media». Studia Historica. Historia Medieval, 1991, vol. IX, p. 75), no hemos considerado necesario reducirlos a gramos de plata. Agradecemos a Mario García Zúniga su colaboración para elaborar este cuadro. 
JOSÉ RAMÓN DÍAZ DE DURANA Y ARSENIO DACOSTA

TITULARIDAD SEÑORIAL, EXPLOTACIÓN Y RENTAS DE LOS RECURSOS AGRÍCOLAS,

GANADEROS Y FORESTALES EN EL PAÍS VASCO AL FINAL DE LA EDAD MEDIA

\begin{tabular}{|l|r|r|r|r|c|}
\hline & Ingresos & \% & Gastos & Saldo & \% \\
\hline Trigo & 729,00 & 3,05 & 729,00 & & \\
\hline Cebada & 745,51 & 3,12 & 745,51 & & \\
\hline Total & $23.872,11$ & & $10.850,51$ & $13.021,60$ & 54,55 \\
\hline & & & & & \\
\hline 1406 & & & & & \\
\hline Moneda vieja & $13.898,80$ & 62,83 & & & \\
\hline Moneda nueva & $4.724,00$ & 21,35 & & & \\
\hline Total moneda & $18.622,80$ & 84,18 & $7.841,00$ & & \\
\hline Trigo & $2.862,00$ & 12,94 & 729,00 & & \\
\hline Cebada & 637,26 & 2,88 & 745,51 & & \\
\hline Total & $22.122,06$ & & $9.315,51$ & $12.806,55$ & \\
\hline
\end{tabular}

\section{LA GESTIÓN DE LOS BIENES RÚSTICOS DE LOS SEÑORES SIN SEÑORÍO}

En Vizcaya y Guipúzcoa los parientes mayores no fueron titulares de señoríos jurisdiccionales ${ }^{56}$. Su dominio sobre las tierras y los hombres situados bajo su ámbito de influencia tenían como referencia su patronazgo sobre las iglesias que entendían como una suerte de señorío ${ }^{57}$. Se trataba, por tanto, de señores sin señorío que, gracias a los patronatos, eran titulares de tierras que explotaban campesinos sometidos a censos. Apoyándonos en los testimonios conservados sobre la explotación de recursos del sector primario pertenecientes a las iglesias de patronato laico, en los memoriales de bienes, en la vinculación de bienes a mayorazgos o en la valoración de bienes que nos han llegado de distintos linajes de parientes, intentaremos perfilar las características de su gestión sobre los recursos agrícolas, ganaderos y forestales en esos territorios, tanto los de aquellos que gestionaban como titulares de derechos de patronato como los pertenecientes a su patrimonio familiar.

El estudio más reciente sobre la cuestión, que reúne información sobre ambos, es el realizado por José Ángel Lema y José Antonio Munita sobre el linaje de Barroeta, asentado

56 Deben hacerse tres excepciones. Los Avellaneda, linaje de Castilla-Vieja, recibirán del señor de Vizcaya el señorío sobre el valle de Villaverde de Trucíos en tiempos de Pedro I y lo mantendrán hasta 1440. Los Múgica y los Avendaño, principales linajes vizcaínos, serán respectivamente señores de Aramayona (1370) y Villarreal de Álava (1371), por concesión regia en ambos casos (véase: DAcosTA, Arsenio. Los linajes de Vizcaya en la baja Edad Media: poder, parentesco y conflicto. Tesis doctoral. Salamanca, 1997 , pp. 343 y ss).

57 Así lo entienden los Velasco y los Ayala en sus intentos de adquisición de derechos señoriales en territorio vizcaíno - prioritariamente en la ría del Nervión- en el siglo xv, que invariablemente incluyen derechos de patronazgo sobre distintas parroquias rurales (DACOsta, Los linajes de Bizkaia, pp. 127 y ss). 
JOSÉ RAMÓN DÍAZ DE DURANA Y ARSENIO DACOSTA

TITULARIDAD SEÑORIAL, EXPLOTACIÓN Y RENTAS DE LOS RECURSOS AGRÍCOLAS,

GANADEROS Y FORESTALES EN EL PAÍS VASCO AL FINAL DE LA EDAD MEDIA

en la villa vizcaína de Villaviciosa de Marquina ${ }^{58}$. Los Barroeta eran titulares de dos patronatos: San Andrés de Echevarría y Santa María de Jeméin, compartido con los Ugarte y con el concejo de Marquina. Los ingresos procedentes de los mismos eran diversos: diezmos, primicias, ofrendas, rentas derivadas de explotación del monte y del bosque así como de otros bienes inmuebles, tanto rústicos - molinos- como solares urbanos, etc. ${ }^{59}$. En conjunto, los Barroeta ingresaban no menos de $26.000 \mathrm{mrs}$. anuales. Un nivel de ingresos modesto si se compara con datos de otros linajes guipuzcoanos y vizcaínos por el mismo concepto $^{60}$.

Junto a los ingresos procedentes de los patronatos de San Andrés de Echevarría y Santa María de Jeméin, la documentación familiar de los Barroeta nos ha legado un memorial que puede fecharse hacia el año 1497 cuyo título es especialmente expresivo: «Nobles sennores qu'el presente memorial vieren sepan quántos e quáles son las rentas e vienes de los sennores de la casa e solar de Barroeta ${ }^{61}$. Su contenido nos muestra la cuantía y calidad de sus inmuebles y rentas. Como afirman acertadamente Lema y Munita, el memorial «resulta ser una muy fiable descripción a escala, realizada en clave dominial y según la propia percepción que tienen los señores de Barroeta». Tomando como referencia central la propia torre del linaje $\mathrm{e}^{62}$ y la casa solar de Echebarría ${ }^{63}$, se describen los bienes -tierras y manzanales ${ }^{64}$, casas e caserías ${ }^{65}$, participaciones en ferrerías ${ }^{66}$, montes ${ }^{67}$, seles $^{68}$-, los ingresos procedentes de los oficios públicos que desempeñan los miembros del linaje ${ }^{69}$,

58 "Para en honra e sustentamiento. Los patronatos, bienes y rentas de la casa y solar de Barroeta (siglos Xiv-Xvi)». En Munita, Dacosta, Lema, Paz y Díaz de Durana (eds.), "En tiempo de ruydos e bandos», pp. $143-224$.

59 A ellos hay que añadir ofrendas testamentarias, oblaciones, capellanías, cobros de pie de altar y multas judiciales, como ha puesto de relieve Curiel, La parroquia en el País Vasco, pp. 113-136.

60 Por ejemplo, los 537.625 mrs. que ingresaban los Guevara sobre once parroquias de patronato; los 161.500 de los Múgica-Butrón o los 160.000 mrs. de los Loyola. Los Barroeta se sitúan en la amplia mayoría de casas de parientes - un total de treinta y dos- que ingresaban menos de 50.000 maravedís al año. Dacosta, «Patronos y linajes», pp. 25 y ss; Curiel, La parroquia en el País Vasco, pp. 320-332. Adviértase, sin embargo, que lo importante no era solo el montante de los ingresos sino la ascendencia sobre los hombres que habitaban y explotaban las tierras, el monte y el bosque que administraban los Barroeta y los Ugarte.

61 Munita, Dacosta, Lema, Paz y Díaz de Durana (eds.), "En tiempo de ruydos e bandos», doc. 16.

62 «Prymeramente, la casa e torre de Barroeta, con su casería de tierras, e mançanales, e nozedales, e castannales, e montes, pertenesçientes a la dicha casa e casería de Barroeta en su derredor».

63 «Yten, la casa e solar de Echabarría, con la yglesia e monesterio del sennor Sant Andrés de Echabarría, con las tierras e terrenos de al derrededor, con el lugar de fazer unas ruedas enteras junto con la dicha casa. Yten, los diezmos de la dicha anteyglesia y vezinos d'ella, con su patronazgo. Yten, la parte del diezmo de la dicha iglesia, que ha en las tierras de la villa de Marquina».

64 "Yten, la tierra e mançanal de a media ganançia con Pedro de Urcaray».

65 "Yten, en la casa y casería de Varuscayn, que tenga los ganados a medias y más cada anno, diez seys fanegas de trigo, y la quarta parte de la mançana de ochoçientos mançanos que han de tener, y la quarta parte de los castannos, y las tres quartas partes de los montes, e seys requesones, e una cabra de un anno, e quatro capones cada anno, por syenpre».

66 "Yten, la ochaba parte de la ferrería le rueda/ de Agorría».

67 «Yten, las dos partes de los montes de Barrueta Arana».

68 «Prymeramente, el sel de Cortagoytia donde está asentada la iglesia».

69 «Yten, la alcaldía del fuero de la merindad de Marquina, e más la otra alcaldía de las ferrerías del balle de la Rentería de Amallo». 
JOSÉ RAMÓN DÍAZ DE DURANA Y ARSENIO DACOSTA

TITULARIDAD SEÑORIAL, EXPLOTACIÓN Y RENTAS DE LOS RECURSOS AGRÍCOLAS,

GANADEROS Y FORESTALES EN EL PAÍS VASCO AL FINAL DE LA EDAD MEDIA

los procedentes de la tesorería real o del señorío de Vizcaya ${ }^{70}$ y de los derechos de patronato $^{71}$.

En primer lugar, por tanto, un conjunto de bienes rústicos que constituyen los fundamentos de su patrimonio y rentas: caseríos -entiéndanse como unidades de explotación- arrendados a perpetuidad a los campesinos ${ }^{72}$, que combinan la dedicación cerealista con los árboles frutales -especialmente el manzano- y el aprovechamiento integral del monte y del bosque. En esos espacios se abarca, por un lado, la explotación ganadera -en general en contratos de admetería, a media ganancia entre el casero y el titular- en los seles ${ }^{73}$ de verano e invierno entre los que se producen los desplazamientos trasterminantes del ganado, que suponemos mayoritariamente vacuno; por otro, la explotación de recursos forestales dedicados especialmente a las ferrerías, particularmente para la elaboración de carbón.

Con seguridad, los Barroeta eran con los Ugarte los propietarios rurales más importantes de la villa de Villaviciosa de Marquina y de su merindad. Como ha señalado Arsenio Dacosta, no es discutible la orientación agraria del más valer de los linajes vizcaínos en el plano económico ${ }^{74}$. El análisis de la información conservada sobre los ingresos procedentes de los bienes rurales de los Barroeta, corrobora esa afirmación y confirma que, en el caso de este linaje, a finales del siglo xv, continuaban siendo los que generaban más ingresos. La Tabla 1 reúne las rentas de sus casas y caserías. Es cierto que la modestia de las cifras allí recogidas puede plantear dudas, pero a ellas hay que sumar los ingresos de la explotación ganadera y forestal del monte y del bosque, de difícil cálculo por otra parte. Y, sobre todo, como demuestra el memorial de 1497, los ingresos procedentes de las ferrerías, de los oficios públicos o de los ingresos de la tesorería de Vizcaya, del concejo de Marquina o de la Corona no superan en cuantía a los anteriores. Además, los bienes de referencia y sus rentas, no solo deben entenderse en términos de sustento del linaje, también en términos de honra ${ }^{75}$.

70 «Yten, cada anno en la tesorería de Vizcaya, tres mill e çient maravedís. Yten, cada anno en el conçejo de la villa de Marquina, mill maravedís. Yten, cada anno veynte çinco mill maravedís, que su Alteza fizo merçed a Ferrando Ybánnez de Varroeta, por el serbiçio que fizo en lo de San Sebastián».

71 «Yten, la quarta parte de los diezmos de la yglesia le monesterio/ de Santa María de Xeméyn, con su patronazgo de la dicha quarta».

72 Así lo recogen los contratos conservados en el archivo familiar. Munita, Dacosta, Lema, Paz y Díaz de Durana (eds.), «En tiempo de ruydos e bandos», docs. 7, 8, 11, 12, 14, 15, 17, 24 y 26: «Sepan quoantos esta carta de arrendamiento perpetuo de bendida e firmamiento vieren, cómo yo Martín Ruiz de Barroeta, vasallo del rey e la reyna nuestros sennores, patrón del monesterio del sennor Sant Andrés de Echa[va]rría, e cómo yo donna Leonor de Ganboa, muger legítima del dicho Martín Ruiz, sennor e sennora que somos de la casa e solar de Barroeta, que es en la merindad de Marquina».

73 Díaz de Durana, José Ramón. «Para una historia del monte y del bosque en la Guipúzcoa bajomedieval: los seles. Titularidad, formas de cesión y de explotación». Anuario de Estudios Medievales, 2001, vol. 31, n. ${ }^{\circ}$ 1, pp. 49-73. Díaz de Durana, José Ramón y Fernández de Larrrea, Jon Andoni. «Economía ganadera y medio ambiente: Guipúzcoa y el noreste de Navarra en la Baja Edad Media». Revista de Historia Agraria, 2002, vol. 27, pp. 43-64.

74 Dacosta, Los linajes de Bizkaia, p. 112.

75 Así lo explicitaba, por ejemplo, un contrato matrimonial de 1520 entre Martín Ruiz de Barroeta y Jordana López de Unzueta, hija del prestamero mayor de Vizcaya y vecina de Mondragón: "para en honrra e sustentamiento del dicho matrimonio». Munita, Dacosta, Lema, Paz y Díaz de Durana (eds.), "En tiempo de ruydos e bandos», doc. 30 (1520). 
JOSÉ RAMÓN DÍAZ DE DURANA Y ARSENIO DACOSTA TITULARIDAD SEÑORIAL, EXPLOTACIÓN Y RENTAS DE LOS RECURSOS AGRÍCOLAS, GANADEROS Y FORESTALES EN EL PAÍS VASCO AL FINAL DE LA EDAD MEDIA

TABla I.- Conjunto de las rentas de las casas y caserías de Barroeta (c 1497) ${ }^{76}$.

\begin{tabular}{|l|c|c|c|c|c|c|c|c|}
\hline \multicolumn{2}{|c|}{ CASAS Y CASERías } & \multicolumn{2}{c|}{ TRIGO } & \multicolumn{2}{c|}{ OTROS PRODUCtOS } & DiNERO & LOTES \\
\hline Anteiglesia de Jeméin & $2 \mathrm{c} 5 \mathrm{cc}$ & $25 \mathrm{f}$ & $0 \mathrm{~h}$ & $9 \mathrm{cp}$ & $3 \mathrm{cb}$ & $6 \mathrm{rq}$ & $640 \mathrm{mrs}$ & 6 \\
\hline Anteiglesia de Echevarría & $7 \mathrm{c} 17 \mathrm{cc}$ & $42 \mathrm{f}$ & $9 \mathrm{~h}$ & $16 \mathrm{cp}$ & $5 \mathrm{cb}$ & $14 \mathrm{rq}$ & $540 \mathrm{mrs}$ & 20 \\
\hline Totales & $9 \mathrm{c} 22 \mathrm{cc}$ & $67 \mathrm{f}$ & $9 \mathrm{~h}$ & $25 \mathrm{cp}$ & $8 \mathrm{cb}$ & $20 \mathrm{rq}$ & $1.180 \mathrm{mrs}$ & 26 \\
\hline
\end{tabular}

Abreviaturas: c, casa; cc, casa y casería; f, fanegas; h, heminas; cp, capones; cb, cabras, rq, requesones; y mrs, maravedís.

Los Barroeta no son la excepción. La importancia sustancial de los bienes rurales en el patrimonio y las rentas de distintos linajes a finales del siglo XV o principios del siglo XVI puede comprobarse cuando se han conservado memoriales, inventarios o valoraciones de bienes. Es el caso de la casa solar de Arancibia, probablemente los principales propietarios de las anteiglesias de Guizaburuaga y Berriatúa, de quienes conocemos un memorial similar ${ }^{77}$. Descritos en idéntica lógica dominial que en el caso de los Barroeta, sus bienes tienen similares características: una treintena de caserías que pagan tributos sin especificar, participaciones en varios molinos y ferrerías ${ }^{78} \mathrm{y}$, finalmente,

todos los seles y prados e pastos e montes y castańales e mançanales de media ganançia, e otros qualesquier vyenes e rentas, aguas corrientes, estantes, manantes, anexos e pertenezçientes a la dicha casa e solar de Arançibya, asý en el Condado de Viscaya como en la Probynçia de Guipúzcoa, e como en otro qualquier parte, aya e tenga la dicha casa e solar de Arançibya.

Los casos de los Barroeta y los Arancibia son también los de buena parte de los parientes mayores cuyo ámbito de influencia se reducía al estrecho valle en el que se situaba su casa torre. Su condición de patronos de la parroquia del lugar y de principales propietarios rurales en sus áreas de influencia, pese a lo exiguo de sus rentas, les permitía un formidable control sobre las distintas comunidades locales ${ }^{79}$.

En todo caso, no hay que desdeñar la creciente importancia de otras actividades económicas como las procedentes de las ferrerías y del comercio. Este es un fenómeno particularmente visible entre los linajes urbanos más dinámicos. Es posible apreciar su importancia, por ejemplo, en el caso de los Arbolancha, cuyos bienes son conocidos a través de una valoración correspondiente al año 1431, con motivo de un repartimiento

76 Munita, Dacosta, Lema, Paz y Díaz de Durana (eds.), «En tiempo de ruydos e bandos», pp. 206, 212 y 213.

77 Dacosta, Lema, Munita y Díaz de Durana (eds.), Poder y privilegio, doc. 48.

78 "Yten, la parte de la herrería e mollinos de Ovecola. Yten, la parte de los mollinos de Çubyalde. Yten, la parte de la herrería de Lariz. Yten, los mollinos de Guiçaburuaga» (ibídem).

79 Munita y Lema, «Para en honra e sustentamiento», pp. 143-224; Dacosta, «Patronos y linajes», pp. 21-46; Curiel, La parroquia en el País Vasco-Cantábrico; Díaz de Durana, «Patronatos, patronos, clérigos y parroquianos", pp. 467-508; CATALÁn, Elena. El precio del purgatorio. Los ingresos del clero vasco en la Edad Moderna. Bilbao: Universidad del País Vasco, 2000. 
JOSÉ RAMÓN DÍAZ DE DURANA Y ARSENIO DACOSTA

TITULARIDAD SEÑORIAL, EXPLOTACIÓN Y RENTAS DE LOS RECURSOS AGRÍCOLAS,

GANADEROS Y FORESTALES EN EL PAÍS VASCO AL FINAL DE LA EDAD MEDIA

en la villa de Bilbao ${ }^{80}$. Se trata de un patrimonio diversificado en el que predominan los solares urbanos en distintas ubicaciones de la villa pero donde no faltan huertas, parrales, manzanales, caserías, molinos, hornos y ferrerías en las anteiglesias cercanas. En conjunto su patrimonio está valorado en 99.340 mrs., de los cuales 54.000 se corresponden con la valoración del «mueble e dineros» -una cantidad muy superior a la ingresada anualmente por los Barroeta- procedente, sin duda, de sus actividades comerciales. También es posible observarlo en el testamento de Ochoa Báñez de Artazubiaga de Mondragón, en 1466: dentro de la villa, junto a varios solares urbanos, es titular de tres ferrerías y dos solares de ferrerías y otros tres extramuros. Tenía, además, participaciones en cinco veneras y era propietario de caserías, huertas, tierras, árboles frutales, robles, montes y molinos ${ }^{81}$. La importancia de las ferrerías y del comercio puede apreciarse también con motivo de la vinculación de bienes al mayorazgo de Tristán de Leguizamón y su esposa en 1479: la casa torre de la calle Somera, solares urbanos, molinos, montes, una casería, cuatro ferrerías -dos de ellas al 50\%-, 12.440 mrs. situados en el pedido y rentería de Bilbao ${ }^{82}$. Finalmente, lo mismo puede decirse de los Mans Engómez, prebostes de San Sebastián: una casa torre, casas en los arrabales, huertas y casas entre la villa y Hernani, caserías con sus tierras, manzanales, ganados y montes, un molino, situados en las alcabalas -45.000 mrs.-, objetos de plata, etc. A finales del siglo xv, el linaje Engómez es considerado como «de personas poderosas e letrados e de mucho caudal $»^{83}$.

A mediados del siglo xv se constata ya una intensa diversificación de las fuentes de renta de los hidalgos vizcaínos y guipuzcoanos. Las actividades mercantiles y las asociadas a la producción y comercialización del hierro implican un cambio sustancial en las haciendas de los parientes mayores. Todos los estudios realizados para las élites vizcaínas y guipuzcoanas del siglo Xv -a pesar de su carácter eminentemente cualitativo- coinciden en la multiplicación de recursos por esta vía y la oportunidad para los parientes mayores y para todos aquellos hidalgos -y no hidalgos- que no compartían la base agraria de los primeros ${ }^{84}$. Un excelente ejemplo lo hallamos en el caso del famoso cronista y banderizo Lope García de Salazar, cuyas rentas anuales se calculan en medio millón de maravedís hacia 1471, la mitad de las cuales -si no más- provienen del sector ferrón, de los tributos por la actividad minera al oeste del Nervión y del control de las actividades comerciales

80 Dacosta, Lema, Munita y Díaz de Durana (eds.), Poder y privilegio, doc. 24.

81 Achón, José Ángel. «A voz de concejo». Linaje y corporación urbana en la constitución de la Provincia de Gipuzkoa. San Sebastián: Diputación Foral de Gipuzkoa, 1995, pp. 133 y ss.

82 García Fernández, Ernesto. Gobernar la ciudad en la Edad Media. Oligarquías y élites urbanas en el País Vasco. Vitoria: Diputación Foral de Álava, 2004, pp. 306-307.

83 Tena, M.a Soledad. «Los Mans Engómez: linaje dirigente de la villa de San Sebastián». Hispania, 1993, vol. LIII, n. ${ }^{\circ}$ 185, pp. 987-1008, particularmente pp. 1004 a 1006.

${ }_{84}$ Aguinagalde, Francisco de Borja de. «Notas sobre los niveles estamentales más elevados de la estratificación social en Guipúzcoa en 1450-1550. La zona del Bajo Urola». Boletín de Estudios Históricos sobre San Sebastián. Homenaje a J. Ignacio Tellechea Idígoras. I, 1982-1983, vol. 16-17 (I), pp. 304-340; TenA, «Los Mans Engómez», pp. 1004 y ss.; AchóN, «A voz de concejo». Linaje y corporación, pp. 137 y ss.; MARÍN Paredes, «Semejante Pariente Mayor», pp. 164 y ss. Un estado de la cuestión en Dacosta, «Las fuentes de renta del linaje de Salazar», pp. 43-64. 
JOSÉ RAMÓN DÍAZ DE DURANA Y ARSENIO DACOSTA

TITULARIDAD SEÑORIAL, EXPLOTACIÓN Y RENTAS DE LOS RECURSOS AGRÍCOLAS, GANADEROS Y FORESTALES EN EL PAÍS VASCO AL FINAL DE LA EDAD MEDIA

en la ría ejercido desde la prebestad de Portugalete ${ }^{85}$. En cuanto a lo segundo, podemos recordar a Martín Ibáńez de Marquina, vecino de Villaviciosa, segundón de linaje, cuyos bienes en el momento de testar al filo del 1500 se valoran en más de dos millones de maravedís, todos ellos obtenidos de sus negocios vinculados al sector ferrón, al transporte marítimo y, sobre todo, al corso ${ }^{86}$.

Estos nuevos sectores y actividades, sumamente rentables, no desvirtuaron la base agraria del poder de los parientes mayores. En la estrecha escala local o comarcal en la que se desenvuelve su influencia, los parientes mayores son grandes propietarios rurales. Tanto si se trata de tierras asociadas al patronato de las iglesias como a los bienes privativos del linaje, combinan la cesión de tierras a perpetuidad a los campesinos con los contratos de aparcería o a media ganancia de fruto, estos últimos ligados a los cultivos leñosos, particularmente en el caso de los manzanales ${ }^{87}$, o contratos de admetería, a media ganancia de ganado. Junto a las rentas - esencialmente en especie que debían pagar por San Martín-, obligaban a los arrendatarios al mantenimiento de la casa, a moler los granos en el molino del patrón, a entregar los diezmos y primicias, a respetar el derecho de retracto, etc. El incumplimiento de sus obligaciones durante tres años implicaba la expulsión de la explotación ${ }^{88}$. Este tipo de contratos no solo era utilizado por el conde de Ońate en las tierras de sus iglesias de patronazgo laico - monasterios de San Miguel de Ońate, Santa Marina de Oxirondo y San Juan de Vergara-, o por instituciones religiosas como el convento dominico de Quejana en Ayala, la abadía de Cenarruza en Vizcaya o la colegiata de Roncesvalles en sus posesiones guipuzcoanas ${ }^{89}$. También por los nuevos grupos emergentes enriquecidos por el transporte o el comercio, como el maestre de naos de Motrico, Sancho de Aguirre, que entregó a Juan de Ascain y a su mujer María de Areizaga

en renta e censo perpetuo para agora e para sienpre jamas [...] la casa e casería de Maya, mía propia, con sus tierras de pan llebar e vinas e con todo otro a ella pertenesçido e montes e prados e pastos e huertas e castañales e nogales e mançanales ${ }^{90}$.

La diferencia sustancial entre la gestión del pariente mayor y el maestre de naos es que este último tomó un mayor control sobre la producción, imponiendo nuevas obligaciones: detallando, en el caso de la producción de vino, las labores que debían aplicarse a las vińas y exigiendo el traslado de la uva al lagar del arrendador, y obligando a

85 Aguirre Gandarias, Sabino. Lope Garcia de Salazar. El primer historiador de Bizkaia (1399-1476). Bilbao: Diputación Foral de Bizkaia, 1994, pp. 135 y ss. Sobre los problemas de los cálculos de este estudio, véase Dacosta, «Las fuentes de renta del linaje de Salazar», pp. 51 y ss.

86 Dacosta, "Las fuentes de renta del linaje de Salazar», pp. 59 y ss.

87 García de Cortázar et álii, Vizcaya en la Edad Media, vol. II, pp. 47-53.

88 DíAz de Durana, «El mundo rural guipuzcoano», pp. 85-91.

89 El mejor estudio de caso hasta la fecha es la tesis doctoral inédita (defendida en noviembre de 1995) de Muro, Robert. La colegiata de Cenarruza, Vizcaya (siglos XIV-XVI). Economía y sociedad de un señorio parroquial y vida de su comunidad monástica, dirigida por María Isabel del Val Valdivieso.

90 Archivo Municipal de Mutriku, leg. 220 (1528). Díaz de Durana, «El mundo rural guipuzcoano», p. 91. 
JOSÉ RAMÓN DÍAZ DE DURANA Y ARSENIO DACOSTA

TITULARIDAD SEÑORIAL, EXPLOTACIÓN Y RENTAS DE LOS RECURSOS AGRÍCOLAS,

GANADEROS Y FORESTALES EN EL PAÍS VASCO AL FINAL DE LA EDAD MEDIA

los arrendatarios a someterse, en el caso de los manzanos, a una inspección en Santa María de agosto, antes de realizar el pago correspondiente. Endureció, además, las condiciones de la relación contractual ${ }^{11}$.

\section{La CONTABilidad y la gestión del mercader: el Caso de Juan Sánchez de BILBAO}

Pero al final de la Edad Media, la cesión de las explotaciones a perpetuidad o a media ganancia de frutos convive con otras formas de gestión de la tierra en la que los contratos se concertaban a corto plazo. Para analizar este tipo de cesiones contamos con un testimonio que permite analizar la gestión de los bienes rurales que un acaudalado mercader vitoriano había incorporado progresivamente a su patrimonio. Se trata de Juan Sánchez de Bilbao, el Rico, de origen judío, dedicado al comercio de lanas y uno de los mayores prestamistas de la ciudad ${ }^{92}$.

Una parte de su patrimonio, formado por casas, tierras y huertas en las aldeas del entorno de la ciudad, procedía de compras ${ }^{93}$ y también, probablemente, de los préstamos impagados. Conocemos la gestión que el mercader y su hijo realizaron de esos bienes gracias a un texto de cincuenta folios numerados en los que fueron anotando los distintos contratos que concertaban con los campesinos de distintas localidades: un registro privado, destinado al conocimiento de cada uno de los contratos que previamente habían sido registrados ante distintos escribanos de la ciudad. Así, por ejemplo:

Arrendé, por testimonio de Ferrand Sánchez de Cucho, el 23 de septiembre de xc annos, a Juan Rodrigues de Lasarte e a Pedro Ruis, vecinos de Lasarte, e a Juan yjo de Pedro de Elexalde e a Juan de Suso, vecinos de Lasarte, todas las heredades que fasta oy tengo compradas en Gardelegui e Arechavaleta e Lasart eçepto las que compre de Martín de Yrayguy e una pieça que está pegada a la rueda por diez años. Recibiéronlas a renta el dicho Pero Ruys e Juan Guerra e Martín de Lascano vecinos de Lasarte de manera común por las dichas xviii fanegas pero entiéndase que han de ser mayores por Ximón Peres a xxi de septiembre de quinientos annos por vi annos ${ }^{94}$.

91 DíAz de Durana, «El mundo rural guipuzcoano», pp. 91-95.

92 Juan Sánchez de Bilbao fue asesinado el 31 de enero de 1493 por Martín López de Escoriaza - «con una espada que le lançó por su cuerpo»- en la plaza del mercado de la ciudad, apenas dos horas más tarde de haber firmado una obligación - un pańo por valor de 700 mrs.- ante el escribano Juan Fernández de Paternina. Vidaurrázaga, José Luis de. «Los Sánchez de Bilbao de la Casa del Cordón. Linaje de judíos conversos». Sancho el Sabio, 1972, vol. 16, pp. 7-41. Ernesto García Fernández ha estudiado su testamento en «Morir en Vitoria a fines de la Edad Media: la muerte "calculada" del mercader Juan Sánchez de Bilbao". Sancho el Sabio, 1988, vol. 9, pp. 123-136. Este último autor ha estudiado también otros documentos relacionados con el pleito que a su muerte entablan sus hijos en torno a la herencia en Gobernar la ciudad, pp. 326-334.

93 Como otros miembros de la élite de la ciudad: Alfonso Ruiz de Gámiz, escribano de la ciudad de Vitoria compra tierras en la aldea de Estarrona, Archivo Histórico Provincial de Álava, Archivo familiar Gámiz-Viguri, 24276, fols. 343r-346r (1484); y 24277-4 (1489).

94 ARChVa, Pleitos Civiles, Quevedo, 2681-1, fol. 2. 
JOSÉ RAMÓN DÍAZ DE DURANA Y ARSENIO DACOSTA

TITULARIDAD SEÑORIAL, EXPLOTACIÓN Y RENTAS DE LOS RECURSOS AGRÍCOLAS, GANADEROS Y FORESTALES EN EL PAÍS VASCO AL FINAL DE LA EDAD MEDIA

El texto nos ofrece, entre 1482 y 1501, un conjunto de datos sobre la aldea donde se ubica la casa, la pieza, la tierra, la huerta, la marzena, la herraen, en ocasiones el topónimo menor, los arrendatarios, el propietario anterior, la duración del arrendamiento, la renta en especie o, en su caso, en dinero y la fecha en la que se firma el contrato. Estas informaciones resultan de gran interés para avanzar en el conocimiento de la gestión de un mercader sobre sus bienes rústicos. Conviene, sin embargo, destacar también sus carencias -derivadas de la finalidad para la que se elaboró el documento-, porque limitan nuestro análisis ${ }^{95}$. Por ejemplo, la relación de los contratos correspondientes a las distintas parcelas, aunque organizados por aldeas, no permite un seguimiento cabal de su renovación: en ocasiones, los nuevos se acumulan al final después de haber anulado -sobre rayándolo- el texto anterior, mientras que en otras la anulación no va acompańada de un nuevo contrato. Tampoco se informa, salvo en contadas ocasiones, de la extensión de la pieza arrendada, impidiendo establecer una relación con la renta exigida. Finalmente, el estado de conservación del documento nos ha impedido la lectura de una docena de contratos.

Los bienes de los Sánchez de Bilbao objeto de estudio eran en su mayoría parcelas de tierra dedicadas al cereal que arrendaron a los campesinos de las aldeas donde estaban ubicadas. Había, además, otros bienes como las ruedas de Gardélegui y Salinas de Añana, casas en distintas aldeas con sus correspondientes heredades y algunas casas en Vitoria. La gestión de los Sánchez de Bilbao es, ciertamente, la de unos rentistas que no explotan directamente sus tierras. Sin embargo, a diferencia de otros, todos sus contratos son a corto o medio plazo. Tenían, además, un exhaustivo conocimiento de la ubicación y características de los distintos bienes. El texto registra ciento treinta y nueve contratos con fecha, de los cuales en ocho no consta su duración ${ }^{96}$. Los contratos tienen una muy diferente duración: varían entre un mínimo de 1 año y un máximo de 12; sin embargo, su promedio es de 6 años ${ }^{97}$. No se observan diferencias significativas entre la media calculada para cada uno de los ańos y la del total del periodo, aunque puede apuntarse la tendencia a reducir los de mayor duración en las renovaciones, rebajándolos a 6 años.

Algunos ejemplos pueden ayudarnos a iluminar esos datos. En primer lugar, un ejemplo de incremento de renta y reducción del número de años de contrato: el 29 de junio de 1490 Juan López, vecino de Lasarte, tomaba en arriendo por diez años y una renta de 17,5 fanegas de trigo, cuya primera paga sería en agosto de 1491, "las heredades que compré de Martín de Yrarguy» en Gardelegui, Arechavaleta y Lasarte; el 25 de septiembre de 1500 se le volvían a arrendar, pero por seis ańos y 18,5 fanegas (un incremento del 6\%). En segundo lugar, un ejemplo de mantenimiento de la renta y reducción del número de años de contrato: el 23 de septiembre de 1490, también por

95 Este documento fue presentado como prueba en el pleito entablado entre los hijos de Juan Sánchez de Bilbao en torno a la herencia después del asesinato de su padre.

96 Agradecemos a Mario García Zúñiga su colaboración para estudiar y representar gráficamente los datos de referencia.

${ }_{97}$ Media: 6,4; mediana y moda: 6; desviación estándar: 2,0. 
JOSÉ RAMÓN DÍAZ DE DURANA Y ARSENIO DACOSTA

TITULARIDAD SEÑORIAL, EXPLOTACIÓN Y RENTAS DE LOS RECURSOS AGRÍCOLAS,

GANADEROS Y FORESTALES EN EL PAÍS VASCO AL FINAL DE LA EDAD MEDIA

diez años, se arrendaron a varios vecinos de Lasarte, por 18 fanegas de trigo, «todas las heredades que fasta oy tengo compradas en Gardelegui, Arechavaleta y Lasarte, eçepto las que compré de Martín de Yrarguy»; por la misma renta, pero por seis ańos, se renovaba el arriendo el 21 de septiembre de 1500. Y, finalmente, un ejemplo de descenso de renta y reducción del número de años de contrato: se trata de tres piezas en el término de Mendiola que el 25 de enero de 1490 se arrendaron a Juan de San Juan por ocho años y cinco fanegas de trigo; las tomaba el 12 de julio de 1498 Lope de San Juan (¿su hijo?) por cuatro fanegas y dos celemines -un 16\% menos- pero, nuevamente, por seis años. Como promedio, la duración es inferior en los contratos de casas, aunque incluyan también piezas, que en los arriendos en los que solo hay parcelas, pudiéndose estimar en un ańo menos: 5,6 y 6,6 ańos, respectivamente.

Tenemos la impresión de que algunos contratos se habrían renovado, por razones que ignoramos, antes de la fecha de su vencimiento. Así sucede, por ejemplo, con las casas "que tengo en Arcabte [con] una rayn que es junto con las dichas casas e una pieza que compré de Semo de Arcaya e más tres piezas que compré de los herederos de Ozenda de Argandonna e más otras tres piezas que compré de Juan López de Ilarraça». El 18 de octubre de 1486 se arrendaban por seis años y veintidós fanegas de trigo a Juan de Elorriaga y, tres ańos después, el 6 de noviembre de 1489, "arrendelo de nuevo al susodicho por ocho annos», pero por treinta y dos fanegas de trigo ${ }^{98}$. En algunos contratos, la renovación antes de tiempo parece responder a la inclusión de nuevas piezas. Así, el cantero Juan de Amarita y su mujer tomaban en arriendo el 27 de octubre de 1487, por 6 años y 32 fanegas de trigo, las "casas nuevas con ciertas heredades que están deslindadas» en Arriaga; el 12 de noviembre de 1490 se renovaba por otros seis años el contrato con el matrimonio por las casas nuevas de Arriaga "con las heredades que fasta oy ha tenido», pero con una renta de cuarenta y seis fanegas, $y$, además, "ha de dar ella media fanega callando en cada un ańo por la pieza que compré de Gonzalo Diaz»" .

De los 131 contratos, solo se estipula la renta en dinero en cinco $(3,8 \%)$, todos ellos en Vitoria, aunque no se puede establecer una correlación entre arriendos de casas y renta en dinero -tres son de casas y los otros dos de piezas-. Lo que sí es estadísticamente significativo es que la duración media de los contratos en dinero $-2,8$ años- sea notablemente inferior -un $57 \%$ más baja- que la de los contratos en especie: 6,5 años.

98 ARChVa, Pleitos Civiles, Quevedo, 2681-1, fol. 24.

99 ARChVa, Pleitos Civiles, Quevedo, 2681-1, fol. 21. 


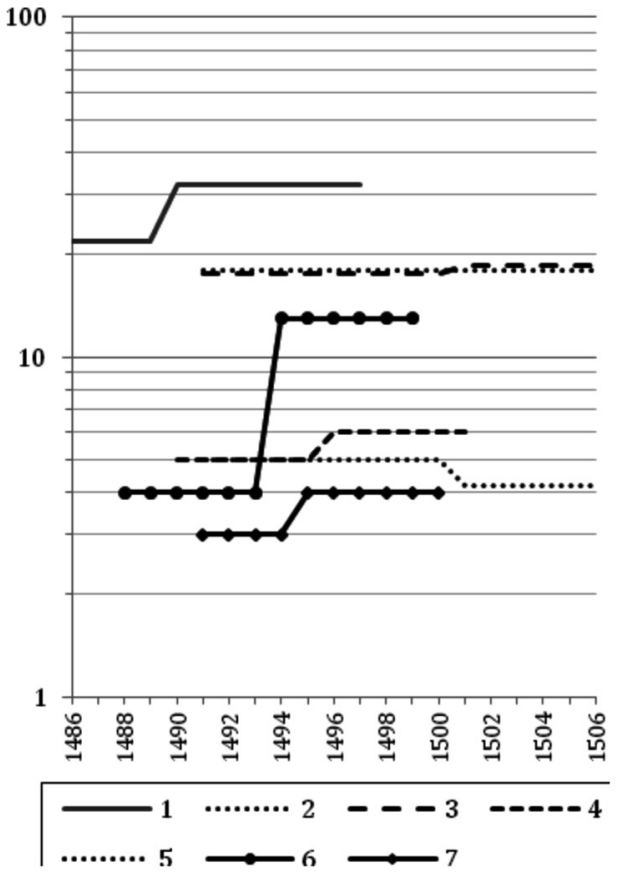

1. «Las casas que tengo en Arcaute, con una rayn que es junto con las dichas casas e una pieza que compré de Semo de Arcaya e más tres piezas que compré de los herederos de Ozenda de Argandonna e más otras tres piezas que compré de Juan López de Ilarraça».

2. "Las heredades que compré de Martín de Yrarguy».

3. Dos piezas en Mendiola.

4. Tres piezas en Mendiola.

5. Una pieza en Gamarra Mayor y Anduzala.

6. «Todas las heredades que fasta oy tengo compradas en Gardelegui, Arechavaleta y Lasarte eçepto las que compré de Martín de Yrarguy».

7. «Unas medias casas que tengo en Gamarra, más una huerta en las que solía vivir Juan Abad de Retana».

Finalmente, por las limitaciones apuntadas, solo hemos podido seguir con seguridad la renovación de siete contratos (Gráfico 1), de los cuales en uno se rebajó la renta -número 5- y en otro se mantuvo -número 2-; en los cinco casos restantes se revisó al alza, con porcentajes de incremento que varían entre un $6 \%$-número 3-y un sorprendente 225\% -número 6-. El 22 de enero de 1487, Rodrigo de Betońo, rodero, arrendaba una pieza en Anduzala (Gamarra Mayor y Menor) por 6 ańos y renta de 4 fanegas de trigo, el primer ańo «a medias». El 25 de octubre de 1493 «tomolas a renta de nuevo" por 13 fanegas y otros seis años. Resulta arriesgado estimar un incremento medio de subida, pero los siete contratos de arrendamiento representados en el gráfico le habrían proporcionado en 1491 -primer año en que coinciden- 84,5 fanegas de trigo, que seis años más tarde habían subido a 95,5 fanegas, lo que supone un 13\% más. Monetizada la renta, la rentabilidad habría sido mucho mayor, de un $51 \%$, cierto que a su favor jugó el aumento de los precios que se produce a partir de 1496-97 debido a las deficientes cosechas ${ }^{100}$.

Un tipo de gestión, en consecuencia, que rompe con los modelos utilizados por los señores jurisdiccionales o los señores sin señorío. El exhaustivo conocimiento de los

100 Bilbao, Luis María. "El precio de los cereales en la ciudad de Vitoria durante el siglo xv (14331513)». En Vitoria en la Edad Media. Vitoria: Ayuntamiento de Vitoria, 1982, pp. 393-406. 
JOSÉ RAMÓN DÍAZ DE DURANA Y ARSENIO DACOSTA

TITULARIDAD SEÑORIAL, EXPLOTACIÓN Y RENTAS DE LOS RECURSOS AGRÍCOLAS,

GANADEROS Y FORESTALES EN EL PAÍS VASCO AL FINAL DE LA EDAD MEDIA

bienes, la gestión cercana que mantienen sobre los mismos, la media de los contratos de arrendamiento, el progresivo descenso del número de años de los contratos en las parcelas documentadas o el demostrado incremento de la renta durante los años de referencia, nos indican que los Sánchez de Bilbao gestionaban su patrimonio rústico buscando el beneficio, aunque este no pueda medirse únicamente en términos económicos. No hemos detectado inversiones en la mejora de las explotaciones agrícolas, pero no son meros receptores de rentas, no se desentienden de las tierras, de su producción. No resulta fácil realizar comparaciones pero, de algún modo, se aproximan a los casos descritos por Cherubini para la Toscana o Siena ${ }^{101}$, y se alejan de la gestión de los bienes rústicos de los mercaderes burgaleses ${ }^{102}$, o de los del Bajo Aragón ${ }^{103}$ con las tierras del cereal, o de los andaluces con el olivar ${ }^{104}$.

Con todo, el beneficio no puede medirse únicamente en términos económicos. Ciertamente, durante los ańos de referencia, la renta de la tierra mantuvo un sostenido crecimiento y los ingresos de los Sánchez de Bilbao, como los de aquellos que percibían rentas en especie, se incrementaron porque la comercialización del trigo en el mercado de Vitoria creció de un modo notable. Ahora bien, ¿̨buscaban solo el beneficio económico? Los ingresos procedentes de las rentas de la tierra representan un escaso porcentaje del total que mayoritariamente tiene su origen, en este caso, en la exportación de lana y en el comercio de paños. Sin embargo, como ya señaló Hilario Casado en referencia a los mercaderes burgaleses, las rentas de la tierra aseguraban el aprovisionamiento de la despensa del mercader en años difíciles sin necesidad de acudir al mercado, extendían su crédito ante sus socios y clientes asentando la confianza en la marca comercial, y les permitían imitar los usos de la nobleza. En el caso que nos ocupa, sin embargo, nos encontramos ante un rico mercader converso, descendiente de judíos, cuyo hijo será acosado por la Inquisición. Como otros mercaderes, Juan y su hijo buscaron el reconocimiento social de los vitorianos. El mejor ejemplo es su propio testamento. En él dispuso su enterramiento en el monasterio de San Francisco, que el día de su muerte y los nueve siguientes participaran en responsos y vigilias todos los clérigos de las cinco iglesias de Vitoria, que a su entierro acudieran, además, cuarenta clérigos de otras tantas parroquias de las aldeas de la ciudad, que a perpetuidad cantaran una misa de réquiem, que se pagara por su trabajo en esas celebraciones a los clérigos y se les diera de comer a ellos y a

101 Cherubini, Giovanni. Signori, contadini, borghesi. Richerche sulla società italiana del Basso Medioevo. Firenze: La Nuova Italia, 1974, pp. 51-119 y 313-426.

102 Casado, Hilario. Señores, mercaderes y campesinos. La comarca de Burgos al final de la Edad Media. Valladolid: Junta de Castilla y León, 1987, pp. 501-510. Aunque, a juicio de Natalia Palenzuela, las inversiones en bienes rústicos de los mercaderes burgaleses instalados en Sevilla buscaban también el beneficio inmediato, en Los mercaderes burgaleses en Sevilla a fines de la Edad Media. Sevilla: Universidad de Sevilla, 2003, pp. 201-209.

103 LaLIENA, Carlos. Sistema social, estructura agraria y organización del poder en el Bajo Aragón en Edad Media (siglos XII-XV). Teruel: Instituto de Estudios Turolenses, 2009, pp. 299 y ss.

${ }_{104}$ El trabajo más reciente sobre la cuestión es el de Borrero, Mercedes. La organización del trabajo. De la explotación de la tierra a las relaciones laborales en el campo andaluz (siglos XIII-XVI). Sevilla: Universidad de Sevilla, 2003, pp. 180 y ss. 

GANADEROS Y FORESTALES EN EL PAÍS VASCO AL FINAL DE LA EDAD MEDIA

los monjes y monjas de los conventos de la ciudad, etc. ${ }^{105}$. Las exequias se pagarán en parte con los ingresos en trigo procedentes de las parcelas de las aldeas. Un conjunto de mandas testamentarias que fueron ejecutadas estrictamente por su hijo, que las anotó por un valor superior a los 300.000 mrs. Junto a ellas -una demostración más de su importancia material y simbólica-, en el expediente judicial que fue presentado ante el juez de la Chancillería, figuran también las rentas que, año a año, entre 1493 y 1500, Juan fue percibiendo de los contratos que su padre había firmado antes de $1493^{106}$. Él continuó aplicando los mismos criterios.

\section{Conclusiones}

Independientemente de su origen, dentro de la élite social nadie parece despreciar las bases agrarias locales, a pesar de que la rentabilidad económica a finales de la Edad Media tiene otras fuentes: el servicio a la Corona, las actividades mercantiles o la producción de hierro. En los casos expuestos hallamos, además de este interés por la renta agropecuaria, otras similitudes notables: la propia lógica económica de un mundo cuya base es esencialmente agraria y la aspiración por mantener y acrecentar la influencia social en un espacio eminentemente rural. Los gastos domésticos de dońa Blanca y doña Leonor, la asfixiante preeminencia de los parientes mayores en sus parroquias rurales o el espectacular despliegue de las honras funerarias de Juan Sánchez de Bilbao, apuntan en un mismo sentido.

Ahora bien, los distintos modelos de gestión de las rentas agrarias revelan divergentes intereses y necesidades. Las señoras de Mártioda integran dichas rentas en la gestión de su señorío, siendo las percepciones feudales parte intrínseca del ejercicio de su poder. El control sobre aparceros y vasallos se inscribe en la lógica del señorío dominical y jurisdiccional y, por ello, no es extrańa una cierta tendencia a la fosilización de las rentas. Los parientes mayores, por su parte, aspirando a lo mismo, pero con limitaciones para acceder a una jurisdicción señorial plena, tratan de someter a comunidades enteras -rurales pero también villanas a través de la presión sobre los comunales- a un control omnímodo que tiene en las parroquias un elemento clave. Estas son el espacio de sociabilidad básico e inevitable, punto de encuentro de la colectividad campesina y no solo por razón del diezmo. No conocemos aún con precisión cómo se articulaban económicamente los contratos agrarios de estos, pero el control de la renta y de los espacios agrarios fue, sin duda, asfixiante, particularmente en relación al monte y al bosque, fuente de materias primas para el suministro de las ferrerías y espacio de localización de estas. En cualquier caso, este control se cimentará a través de distintos mecanismos, particularmente el control de las instituciones del territorio: concejos, oficios regios e instancias jurisdiccionales o sectoriales como las alcaldías de ferrerías. Había mucho en juego y la proximidad de estos señores sin señorío a sus dominados era

105 García Fernández, «Morir en Vitoria a fines de la Edad Media», pp. 129-135.

106 ARChVa, Pleitos Civiles, Zarandona y Wals, O, C 1429/6. 
JOSÉ RAMÓN DÍAZ DE DURANA Y ARSENIO DACOSTA

TITULARIDAD SEŃORIAL, EXPLOTACIÓN Y RENTAS DE LOS RECURSOS AGRÍCOLAS, GANADEROS Y FORESTALES EN EL PAÍS VASCO AL FINAL DE LA EDAD MEDIA

estrecha y dura. Aparte de lo económico estaba en juego su prestigio social y las bases sociológicas de su poder, el oscuro tejido de relaciones interpersonales que convergen en el pariente mayor. Finalmente, el comportamiento de los Sánchez de Bilbao respecto de sus propiedades agrícolas revela un modelo de gestión radicalmente diferente, no menos intenso, en el que se persigue maximizar el beneficio. El mercader ve en el agro un terreno donde invertir y obtener unos ingresos, lejos posiblemente de las rentabilidades de sus otras actividades, pero nada desdeñables y que les permitirán, más adelante, emular a la nobleza local o fundirse con ella. 